Supporting Information

\title{
A Water-Soluble 3D Covalent Organic Framework That Displays Enhanced Enrichment Effect of Photosensitizers and Catalysts for the Reduction of Protons to $\mathrm{H}_{2}$
}

Zhong-Zheng Gao, ${ }^{\dagger}$ Ze-Kun Wang, ${ }^{\dagger}$ Lei Wei, ${ }^{\ddagger}$ Guangqiang Yin, ${ }^{\S}$ Jia Tian, ${ }^{\dagger}$ Chuan-Zhi Liu, ${ }^{\dagger}$ Hui Wang, ${ }^{\dagger}$ Dan-Wei Zhang, ${ }^{\dagger}$ Yue-Biao Zhang, ${ }^{\dagger}$ Xiaopeng Li, ${ }^{\S}$ Yi Liu,,${ }^{*}{ }^{\Uparrow}$ and Zhan-Ting $\mathrm{Li}^{*}, \dagger$

†Department of Chemistry, Shanghai Key Laboratory of Molecular Catalysis and Innovative Materials, Fudan University, 2205 Songhu Road, Shanghai 200438, China

${ }^{\ddagger}$ School of Physical Science and Technology, ShanghaiTech University, Shanghai 201210, China

${ }^{\S}$ Department of Chemistry, University of South Florida, Tampa, Florida 33620, USA

"The Molecular Foundry, Lawrence Berkeley National Laboratory, One Cyclotron Road, Berkeley, California 94720, USA

Corresponding authors: Yi Liu and Zhan-Ting Li

E-mails: yliu@1bl.gov and ztli@fudan.edu.cn 


\section{Synthesis of compounds}
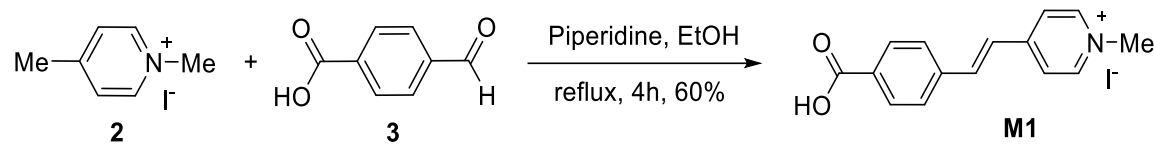

Compound M1. A mixture of compounds $\mathbf{2}^{1}$ (493.6 mg, $2.1 \mathrm{mmol}$ ) and $\mathbf{3}$ (750.7 mg, $2.0 \mathrm{mmol}$ ) in ethanol $(5 \mathrm{~mL})$ and piperidine $(0.01 \mathrm{~mL})$ was stirred under reflux for $4 \mathrm{~h}$ and then cooled to room temperature. To the mixture was added ether $(5 \mathrm{~mL})$ and the resulting precipitate was filtrated and washed with ether and dried in vacuum to give compound M1 as a white solid (0.44 g, 60\%). M.p. > $300{ }^{\circ} \mathrm{C}$ (decomp). ${ }^{1} \mathrm{H}$ NMR (400 MHz, DMSO- $\left.d_{6}\right): \delta 8.86$ (d, $J=6.4$ $\mathrm{Hz}, 2 \mathrm{H}), 8.23, J=6.4 \mathrm{~Hz}, 2 \mathrm{H}), 8.02(\mathrm{~d}, J=16.4 \mathrm{~Hz}, 1 \mathrm{H}), 7.95(\mathrm{~d}, J=8.5 \mathrm{~Hz}, 5 \mathrm{H}), 7.73$ (d, $J=$ $7.9 \mathrm{~Hz}, 2 \mathrm{H}), 7.56(\mathrm{~d}, J=16.4 \mathrm{~Hz}, 1 \mathrm{H}), 4.23-4.28(\mathrm{~m}, 8 \mathrm{H}) .{ }^{13} \mathrm{C}$ NMR $\left(100 \mathrm{MHz}, \mathrm{DMSO}-d_{6}\right): \delta$ 152.0, 145.3, 144.4, 139.4, 129.9, 129.2, 128.4, 128.0, 125.9, 125.3, 123.9, 47.1. HRMS (ESI): Calcd for $\mathrm{C}_{15} \mathrm{H}_{14} \mathrm{NO}_{2}$ : 240.1019[M-I] $]^{+}$. Found: 240.1017 .

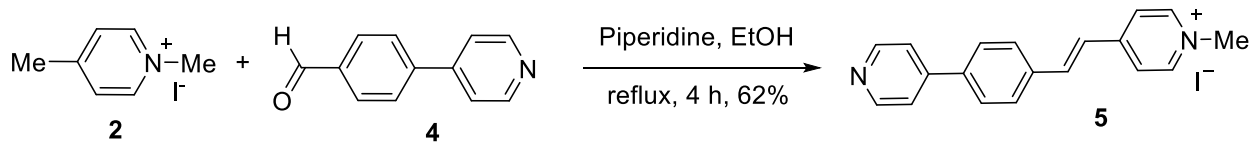

Compound 5. A mixture of compounds $4(1.2 \mathrm{~g}, 6.0 \mathrm{mmol})$ and $2(1.4 \mathrm{~g}, 6.1 \mathrm{mmol})$ in ethanol $(10 \mathrm{~mL})$ and piperidine $(0.1 \mathrm{~mL})$ was stirred under reflux for $4 \mathrm{~h}$ and then cooled to room temperature. To the mixture was added ether $(20 \mathrm{~mL})$ and the resulting precipitate was filtrated and washed with ether and dried in vacuum to give compound $\mathbf{5}$ as a pale yellow solid $(1.48 \mathrm{~g}$, $62 \%$ ). M.p. $280{ }^{\circ} \mathrm{C}$ (decomp.). ${ }^{1} \mathrm{H}$ NMR (400 MHz, DMSO-d $): \delta 8.88(\mathrm{~d}, J=6.8 \mathrm{~Hz}, 2 \mathrm{H})$, $8.68(\mathrm{~d}, J=6.0 \mathrm{~Hz}, 2 \mathrm{H}), 8.25(\mathrm{~d}, J=6.8 \mathrm{~Hz}, 2 \mathrm{H}), 8.07(\mathrm{~d}, J=16 \mathrm{~Hz}, 1 \mathrm{H}), 7.97(\mathrm{~d}, J=8.4 \mathrm{~Hz}$, $2 \mathrm{H}), 7.90(\mathrm{~d}, J=8.4 \mathrm{~Hz}, 2 \mathrm{H}), 7.80(\mathrm{~d}, J=6.0 \mathrm{~Hz}, 2 \mathrm{H}), 7.63(\mathrm{~d}, J=16.4 \mathrm{~Hz}, 1 \mathrm{H}), 4.25(\mathrm{~s}, 3 \mathrm{H})$. ${ }^{13} \mathrm{C}$ NMR $\left(100 \mathrm{MHz}, \mathrm{DMSO}-d_{6}\right): \delta=152.7,150.8,146.3,145.6,140.2,139.0,136.4,129.3$, 127.9, 124.6, 124.1, 121.5, 47.4. HRMS (ESI): Calcd for $\mathrm{C}_{19} \mathrm{H}_{17} \mathrm{~N}_{2}: 273.1386$ [M-I] $]^{+}$. Found: 273.1287.

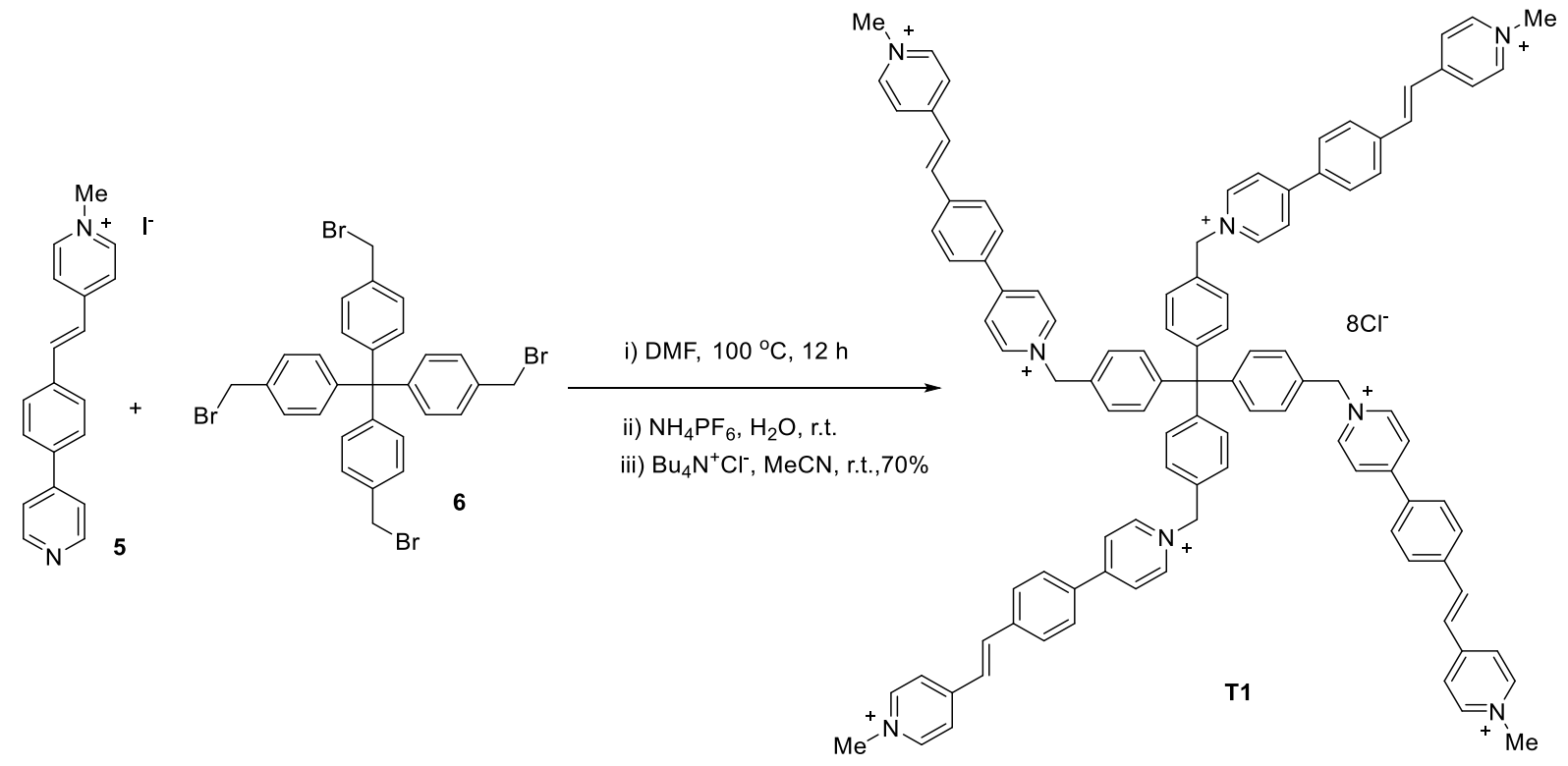


Compound T1. A mixture of compounds $5(0.84 \mathrm{~g}, 2.1 \mathrm{mmol})$ and 6 (0.35 g, $0.5 \mathrm{mmol})$ in DMF (15 mL) was stirred at $100{ }^{\circ} \mathrm{C}$ for $12 \mathrm{~h}$ and then cooled to room temperature. To the mixture was added acetone $(20 \mathrm{~mL})$ and the precipitate formed was filtrated and washed with acetone and dried in vacuum. The resulting solid was further recrystallized from acetonitrile to give a crude product as a reddish solid. The solid was dissolved in water of least amount. To the solution was added dropwise saturated aqueous solution of ammonium hexafluorophosphate until no precipitate was formed. The precipitate was filtrated and washed with cold water and then dissolved in acetonitrile of least amount. To the solution was added dropwise saturated aqueous solution of tetrabutylammonium chloride. The precipitate formed was filtrated and washed with cold acetonitrile and further dried in vacuo to give compound T1 as a reddish solid (0.45 g, 70\%). M.p. $>300{ }^{\circ} \mathrm{C}$ (decomp). ${ }^{1} \mathrm{H}$ NMR (400 MHz, DMSO- $\left.d_{6}\right): \delta$ $9.30(\mathrm{~d}, J=6.4 \mathrm{~Hz}, 8 \mathrm{H}), 8.94(\mathrm{~d}, J=6.4 \mathrm{~Hz}, 8 \mathrm{H}), 8.64(\mathrm{~d}, J=6.4 \mathrm{~Hz}, 8 \mathrm{H}), 8.30(\mathrm{~d}, J=6.0 \mathrm{~Hz}$, $8 \mathrm{H}), 8.24(\mathrm{~d}, J=8.4 \mathrm{~Hz}, 8 \mathrm{H}), 8.14(\mathrm{~d}, J=16.4 \mathrm{~Hz}, 4 \mathrm{H}), 8.01(\mathrm{~d}, J=8.0 \mathrm{~Hz}, 8 \mathrm{H}), 7.78(\mathrm{~d}, J=$ $16.4 \mathrm{~Hz}, 4 \mathrm{H}), 7.51(\mathrm{~d}, J=8.0 \mathrm{~Hz}, 8 \mathrm{H}), 7.25(\mathrm{~d}, J=8.4 \mathrm{~Hz}, 8 \mathrm{H}), 5.83-5.87$ (m, 8H), 4.29-4.33 $(\mathrm{m}, 8 \mathrm{H}) .{ }^{13} \mathrm{C}$ NMR $\left(100 \mathrm{MHz}\right.$, DMSO- $\left.d_{6}\right): \delta 177.8,163.9,162.7,154.4,152.3,147.2,145.8$, 145.4, 139.3, 134.9, 132. 8, 131.3, 129.5, 129. 4, 128.8, 126.3, 125.3, 124.4, 62.1, 47.6. HRMS (ESI): Calcd for $\mathrm{C}_{105} \mathrm{H}_{92} \mathrm{~N}_{8}$ : $183.0925[\mathrm{M}-8 \mathrm{Cl}]^{8+}$. Found: 183.0914.

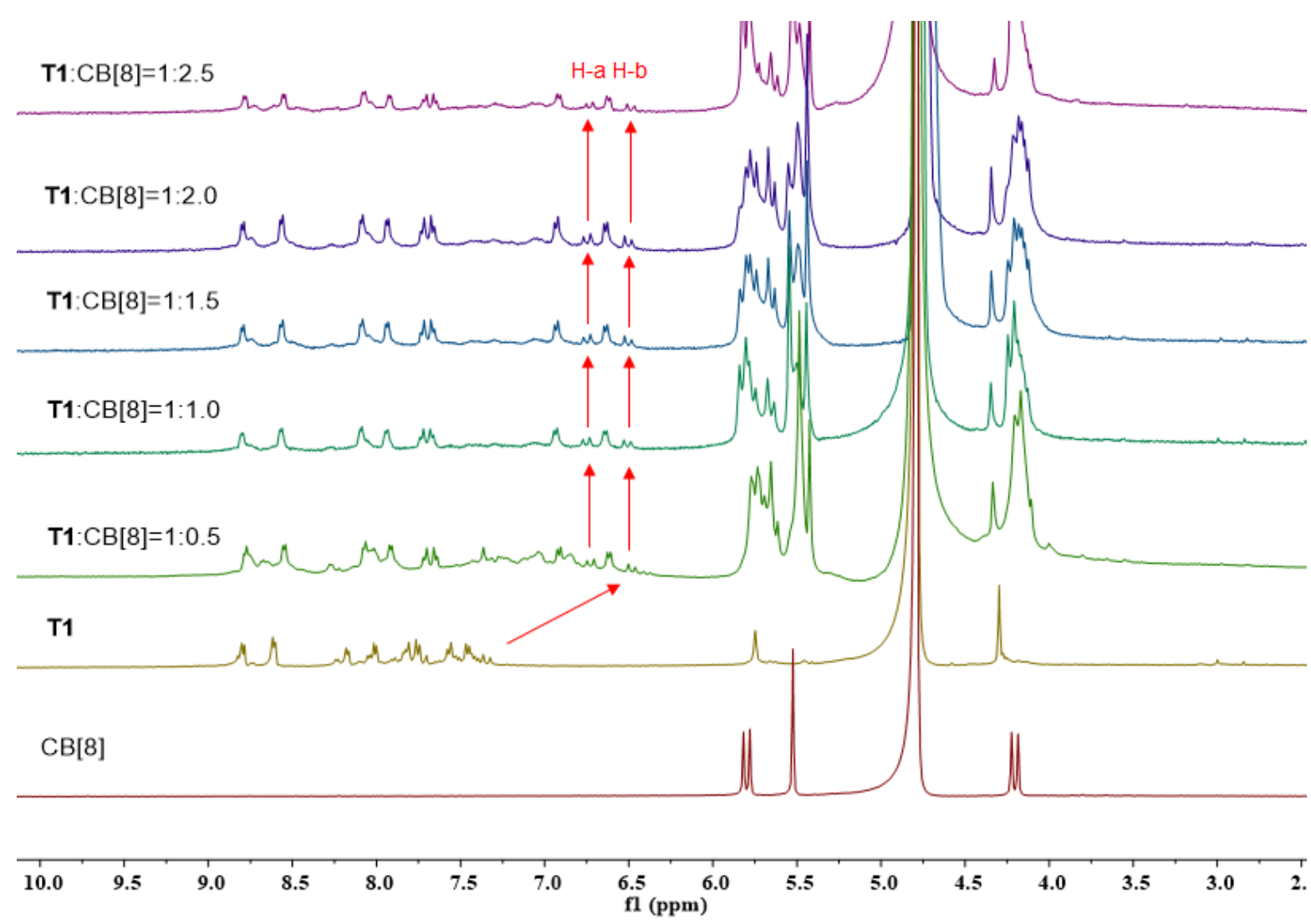

Figure S1. ${ }^{1} \mathrm{H}$ NMR spectrum $(400 \mathrm{MHz})$ of the mixtures of T1 (1.0 mM) and CB[8] (0 to 2.5 equiv) in $\mathrm{D}_{2} \mathrm{O}$ at $25^{\circ} \mathrm{C}$. 


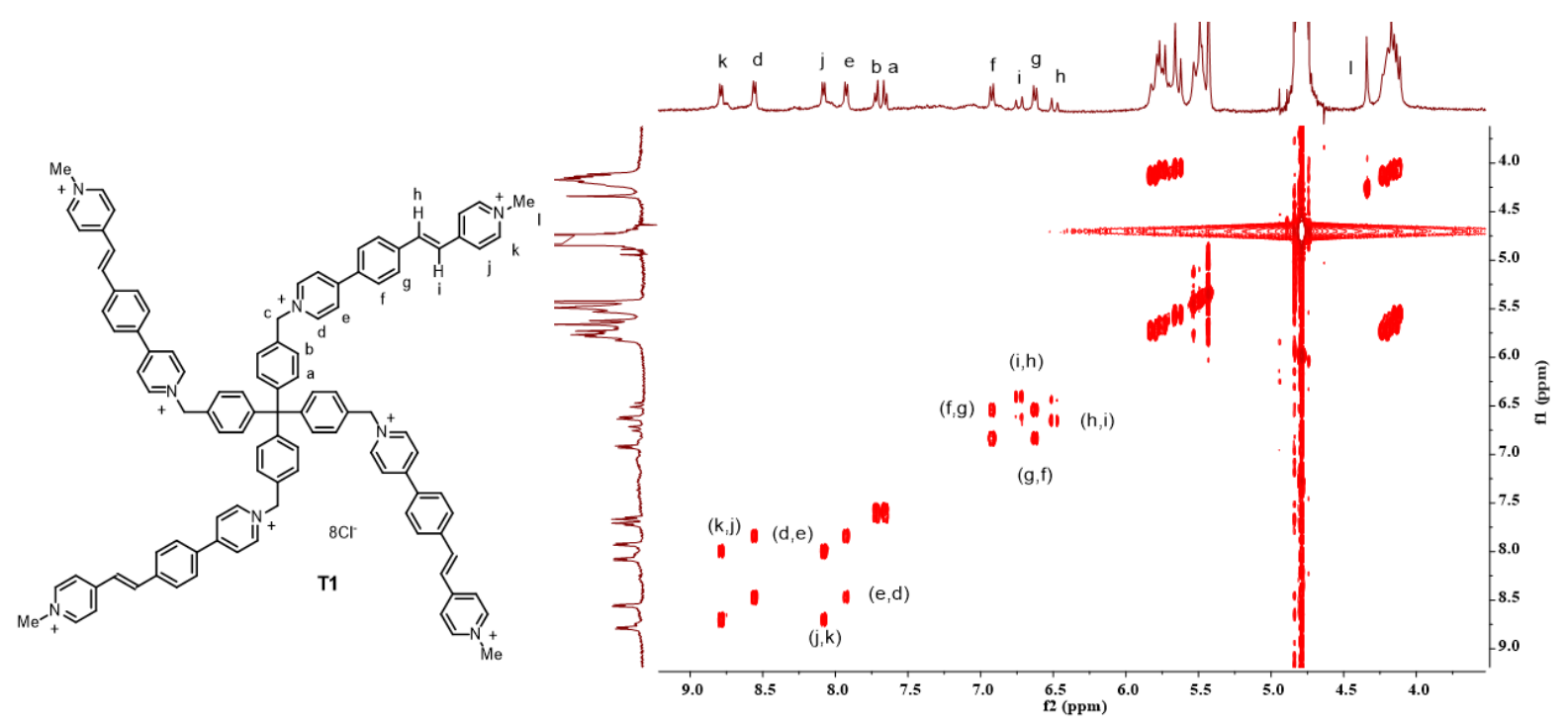

Figure S2. 2D ${ }^{1} \mathrm{H}$ COSY spectrum (400 MHz) of the solution of T1 (1.0 mM) and CB[8] (2.0 $\mathrm{mM})$ in $\mathrm{D}_{2} \mathrm{O}$ at $25^{\circ} \mathrm{C}$.
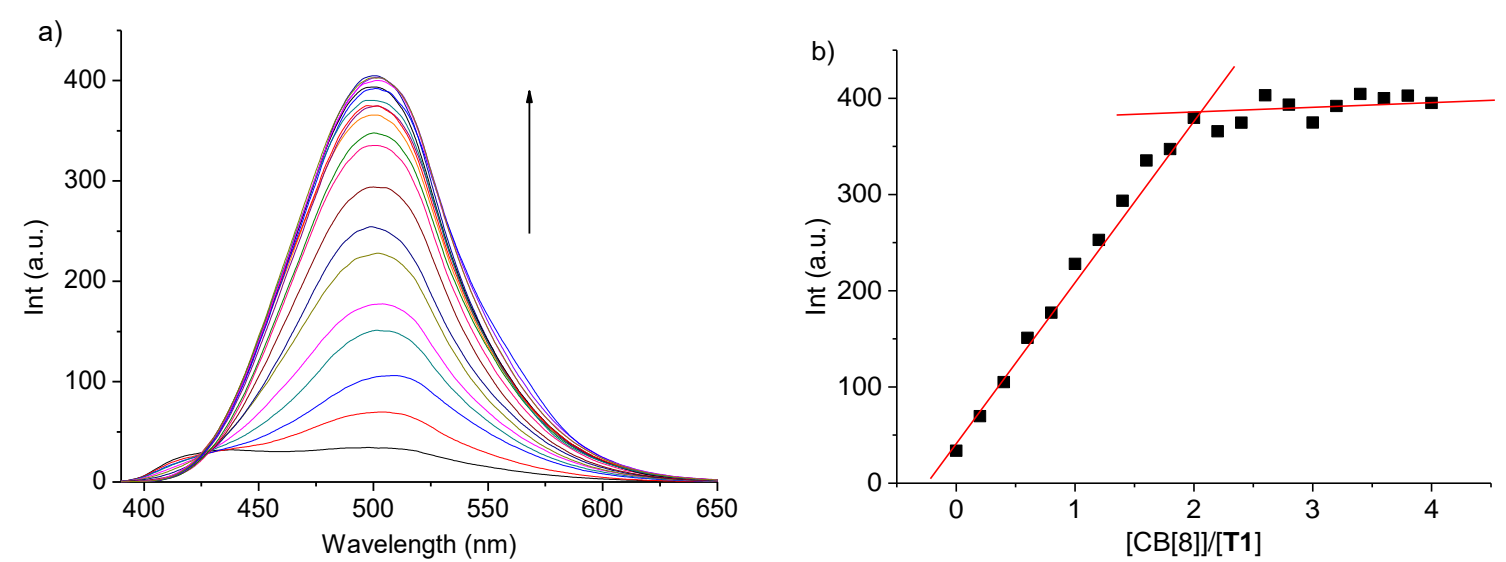

Figure S3. a) Fluorescent spectra of T1 $(10 \mu \mathrm{M})\left(\lambda_{\mathrm{ex}}=360 \mathrm{~nm}\right)$ in the presence of CB[8] (04.0 equiv) in water at $25^{\circ} \mathrm{C}$, and b) emission intensity at $502 \mathrm{~nm}$ vs [CB[8]]/[T1].
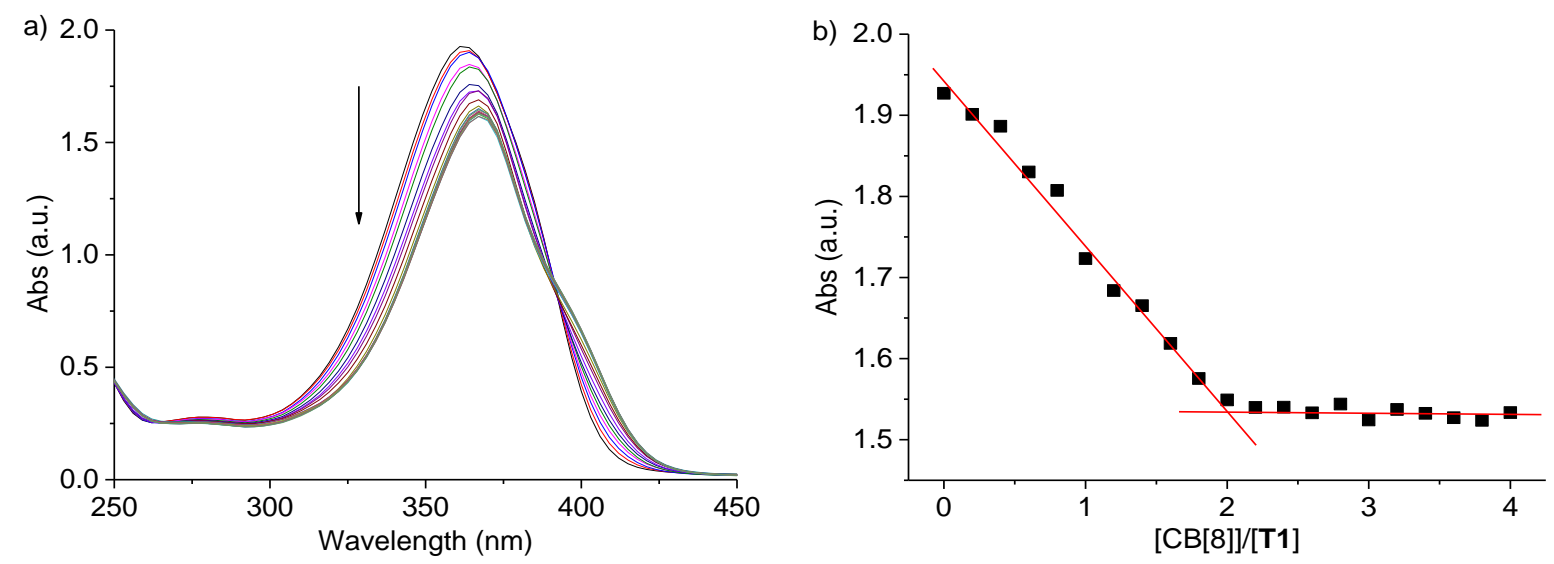

Figure S4. a) UV-vis absorption spectra of $\mathbf{T 1}(10 \mu \mathrm{M})$ in the presence of $\mathrm{CB}$ [8] (0-4.0 equiv) in water at $25^{\circ} \mathrm{C}$, and b) maximum absorbance vs [CB[8]]/[T1]. 


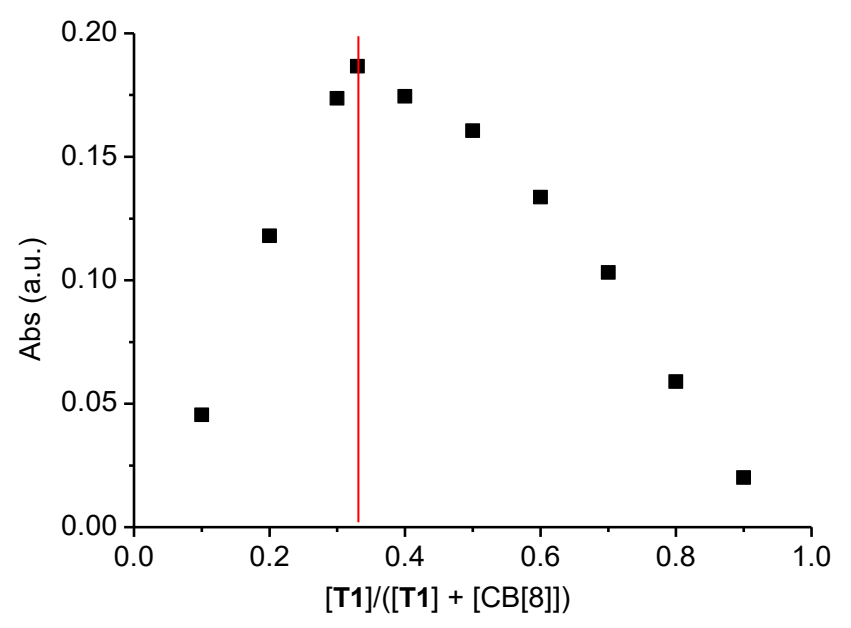

Figure S5. Job's plot obtained from the absorption spectra of the mixtures of $\mathbf{T} 1$ and $\mathrm{CB}[8]$ $([\mathrm{T} 1]+\mathrm{CB}[8]=50 \mu \mathrm{M})$ in water at $25^{\circ} \mathrm{C}$.

a)

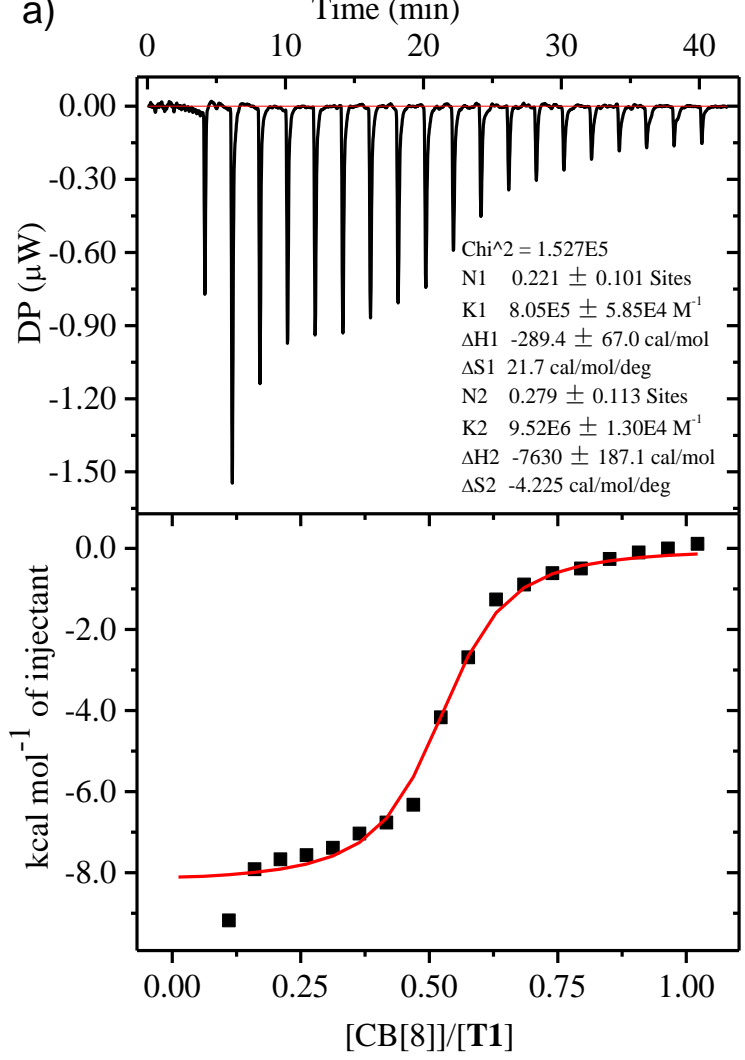

b)

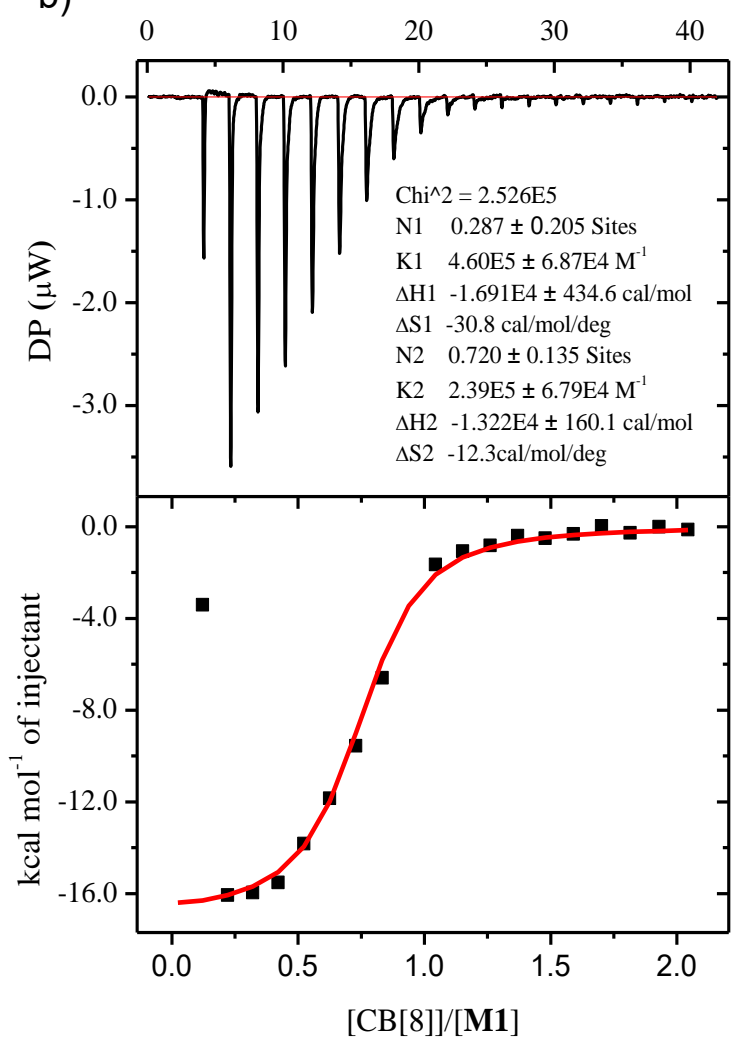

Figure S6. a) Isothermal titration thermogram of T1 $(0.5 \mathrm{mM})$ titrated into the solution of CB[8] $(0.1 \mathrm{mM})$ in water at $25^{\circ} \mathrm{C}$, and b) isothermal titration thermogram of M1 (1.0 mM) titrated into the solution of $\mathrm{CB}[8](0.1 \mathrm{mM})$ in water at $25^{\circ} \mathrm{C}$. 

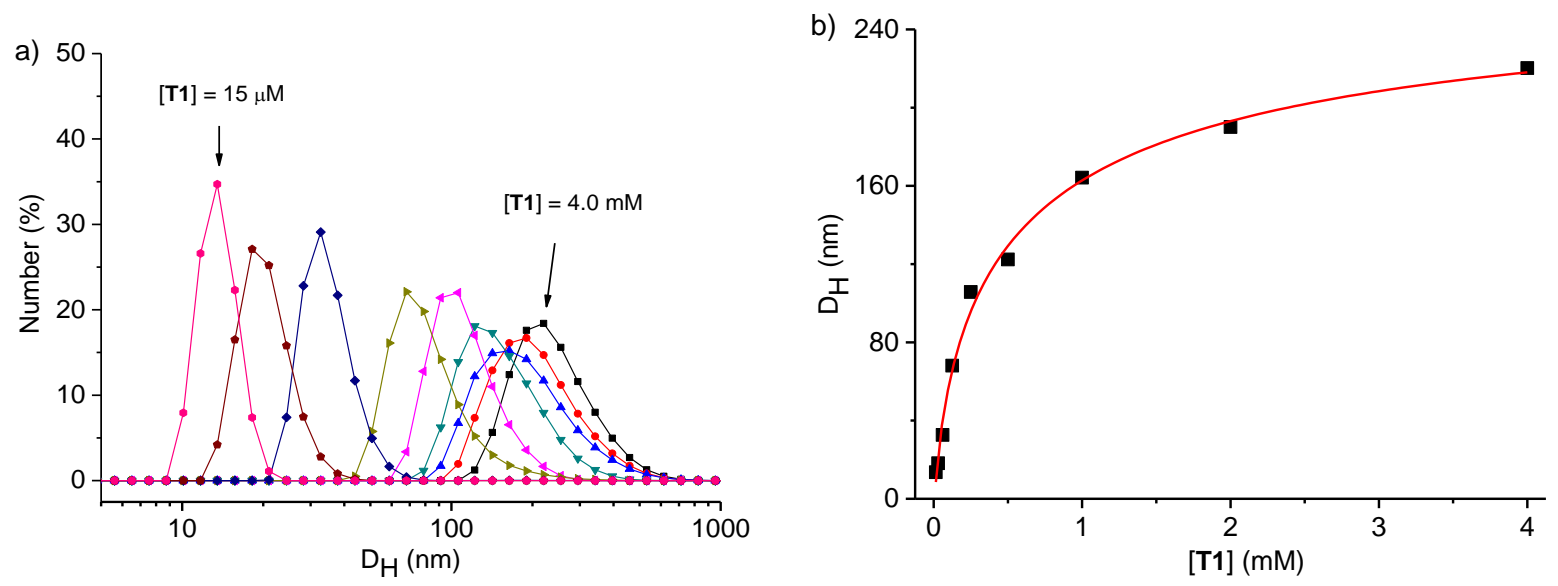

Figure S7. a) DLS profile of SOF-s $([\mathrm{T1}]=15 \mu \mathrm{M}$ to $4.0 \mathrm{mM})$ in water at $25^{\circ} \mathrm{C}$. b) The plot of $D_{H}$ vs [T1].

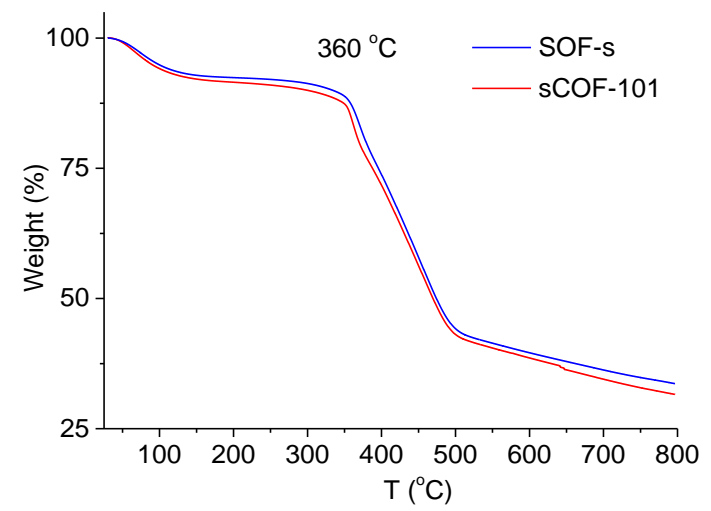

Figure S8. Thermogravimetric analysis thermogram of sCOF-101 and SOF-s.

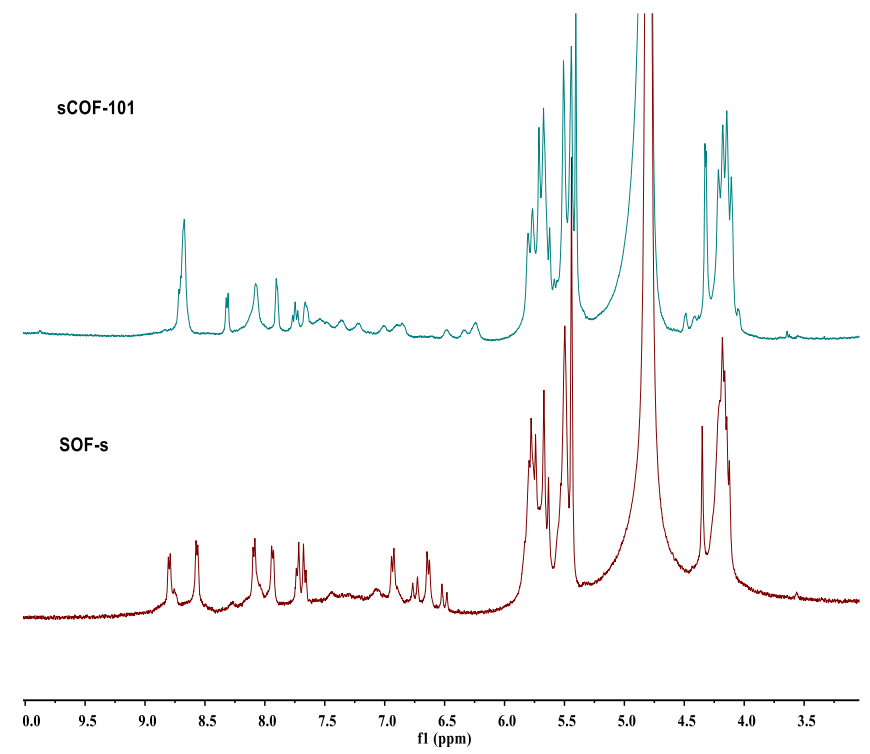

Figure S9. ${ }^{1} \mathrm{H}$ NMR spectra $(400 \mathrm{MHz})$ of sCOF-101 and SOF-s $([\mathrm{T1}]=1.0 \mathrm{mM})$ in $\mathrm{D}_{2} \mathrm{O}$ at $25^{\circ} \mathrm{C}$ after irradiation with visible light for 0 and 4 hours. 


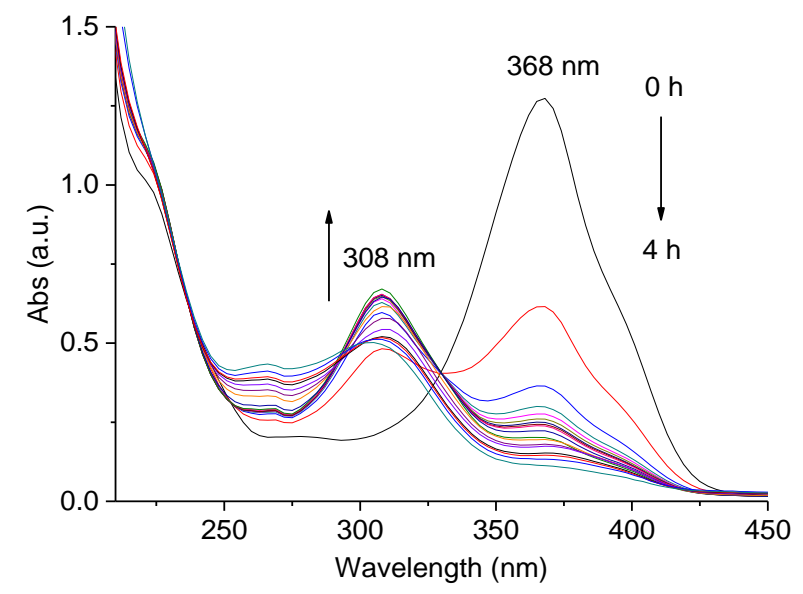

Figure S10. UV-vis absorption spectra of SOF-s $([\mathrm{T1}]=10 \mu \mathrm{M})$, highlighting visible light irradiation-induced weakening of the absorption band centered around $368 \mathrm{~nm}$ and the generation of the band centered around $308 \mathrm{~nm}$.

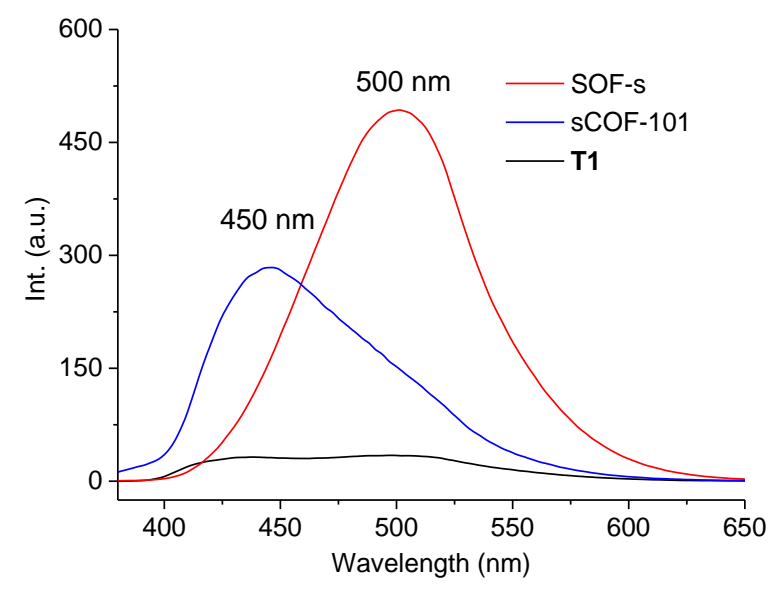

Figure S11. The fluorescent spectrum of sCOF-101, SOF-s, and T1 in water at $25^{\circ} \mathrm{C}([\mathbf{T 1}]=$ $10 \mu \mathrm{M})$.
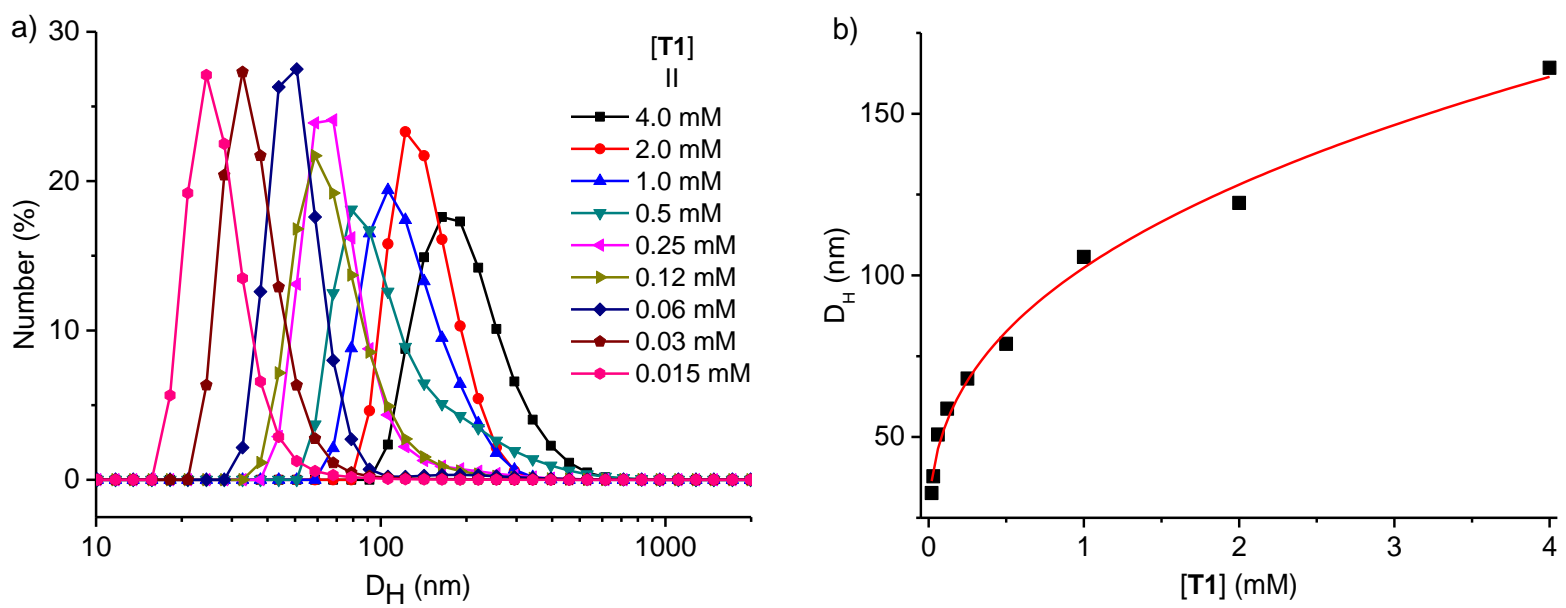

Figure S12. DLS profiles of sCOF-101 in water at $25{ }^{\circ} \mathrm{C}$. The samples were prepared by irradiating the corresponding SOF-s $([\mathbf{T 1}]=15 \mu \mathrm{M}$ to $4.0 \mathrm{mM})$ solutions with visible light for 4 hours. 


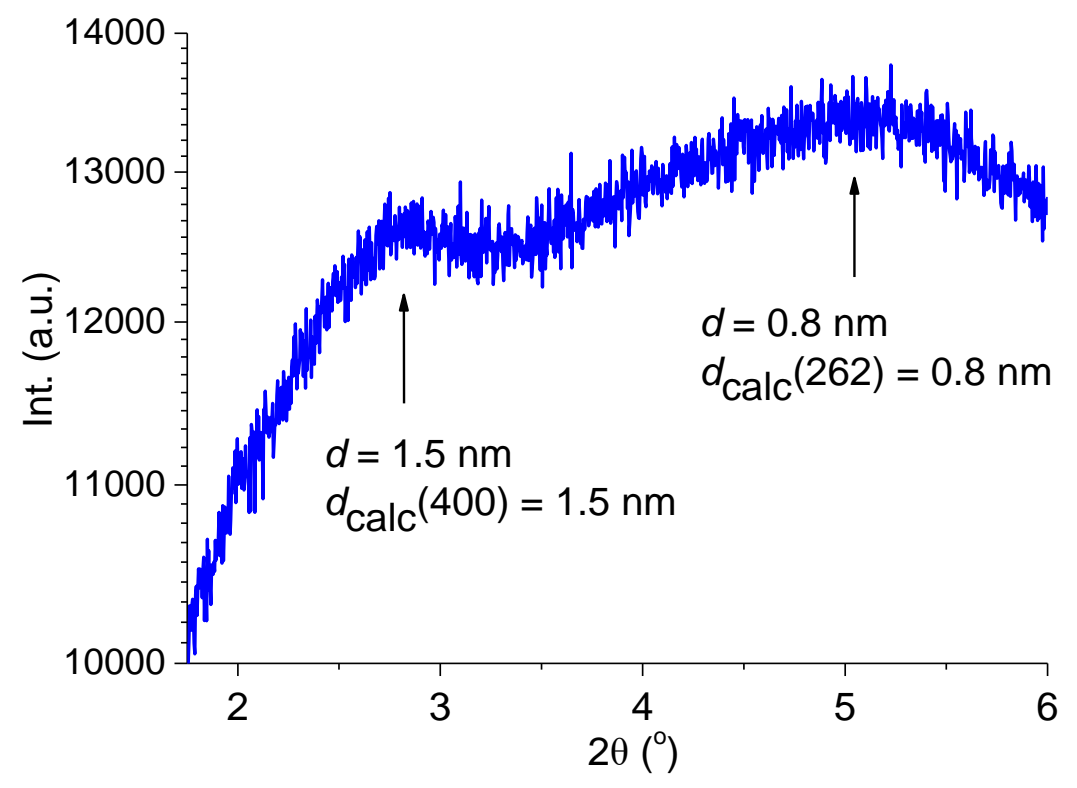

Figure S13. The synchrotron XRD profile of sCOF-101 microcrystals. The samples were obtained by slow evaporation of their solution in water.

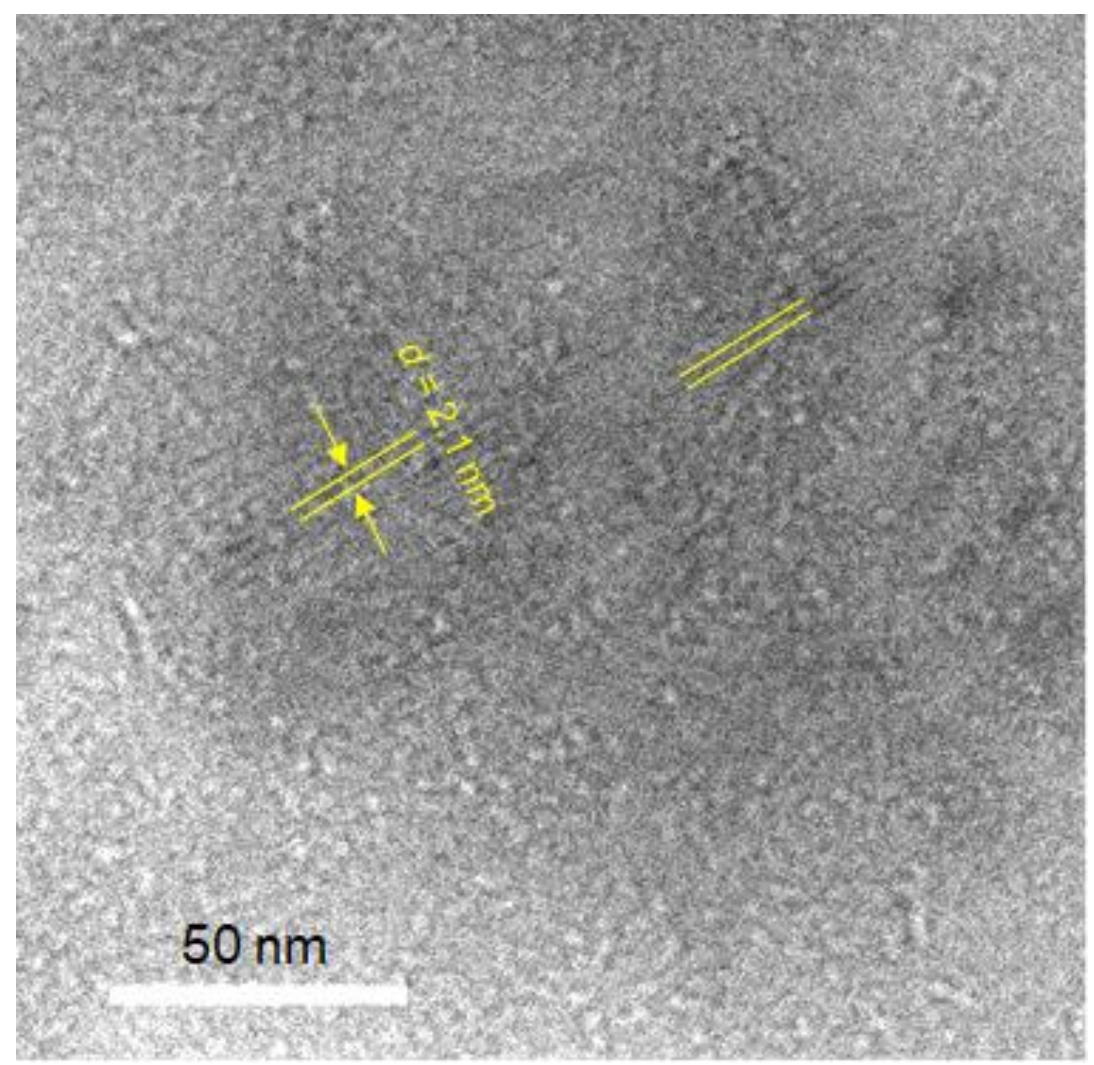

Figure S14. High resolution TEM image of sCOF-101. 

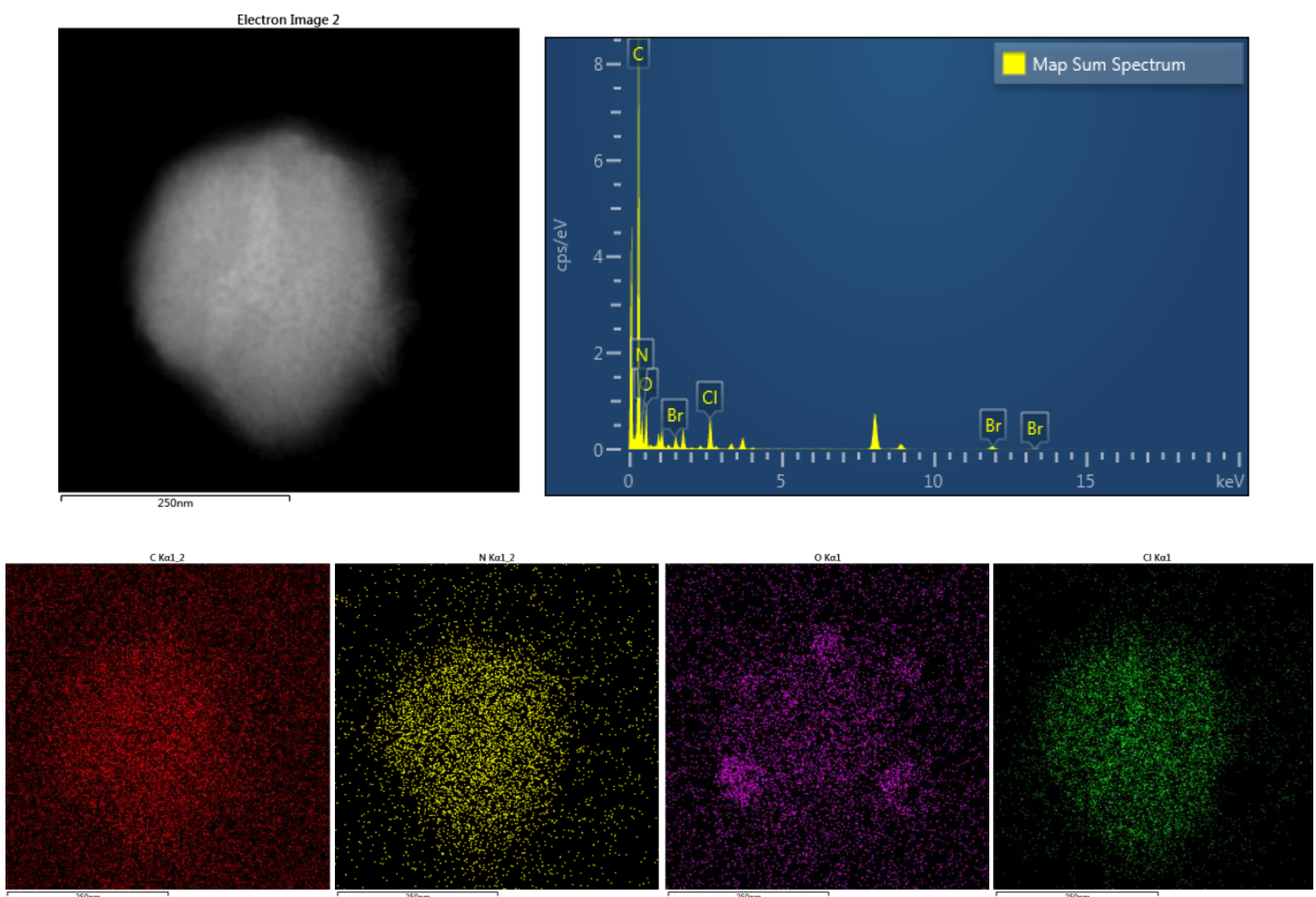

Figure S15. The energy-dispersive X-ray spectroscope of SOF-s and the related element distribution mapping images, confirming the composition of the $\mathrm{C}, \mathrm{N}, \mathrm{O}$ and $\mathrm{Cl}$ elements.
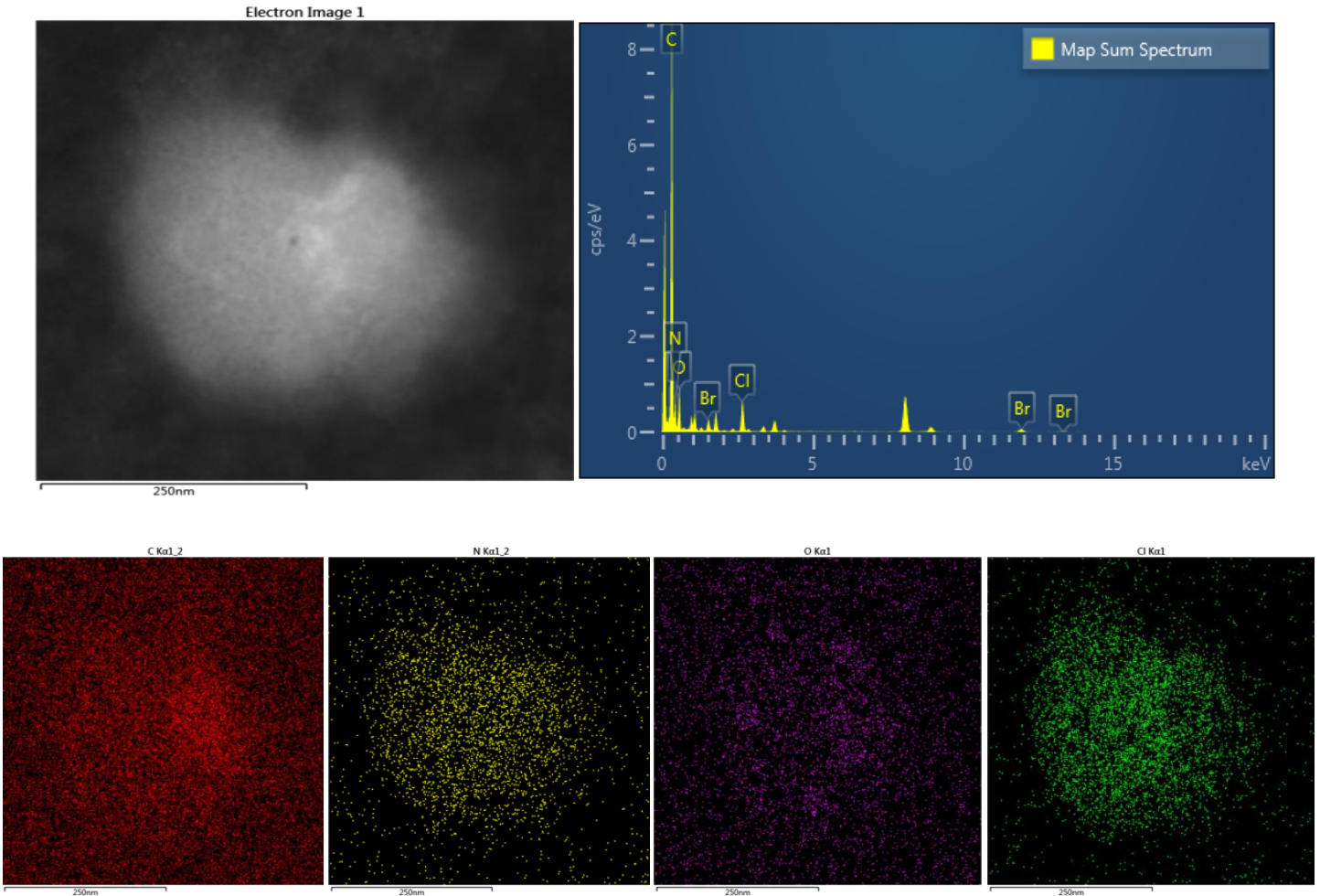

Figure S16. The energy-dispersive X-ray spectroscope of sCOF-101 and the related element distribution mapping images, confirming the composition of the $\mathrm{C}, \mathrm{N}, \mathrm{O}$ and $\mathrm{Cl}$ elements. 


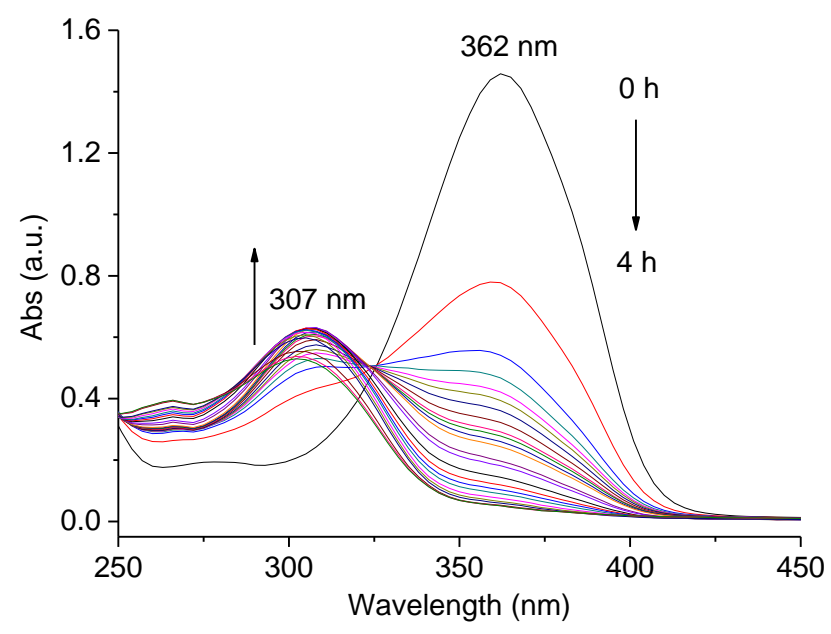

Figure S17. UV-vis absorption spectra of T1 $(10 \mu \mathrm{M})$, highlighting visible light irradiationinduced weakening of the absorption band centered around $362 \mathrm{~nm}$ and the generation of the band centered around $307 \mathrm{~nm}$.

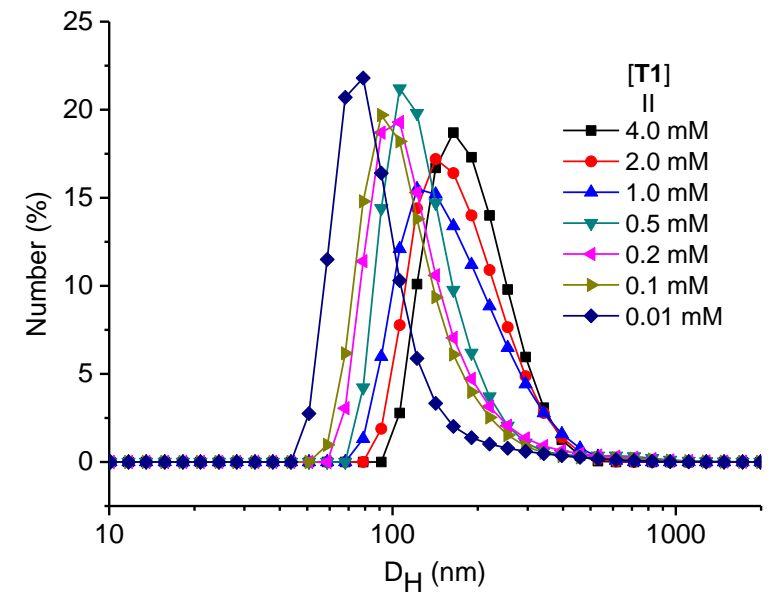

Figure S18. DLS of the solution of P-irr (the concentration related to T1). The P-irr solution was prepared by irradiating the solution of $\mathbf{T 1}(4.0 \mathrm{mM})$ in water with visible light at $25{ }^{\circ} \mathrm{C}$ for 4 hours and diluted to the indicated concentration before subjecting to the measurement.

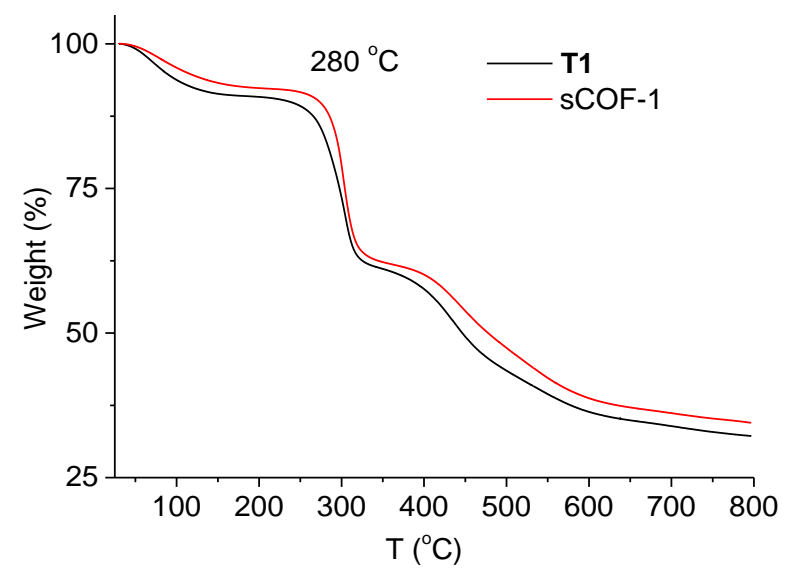

Figure S19. Thermogravimetric analysis thermogram of T1 and P-irr. 


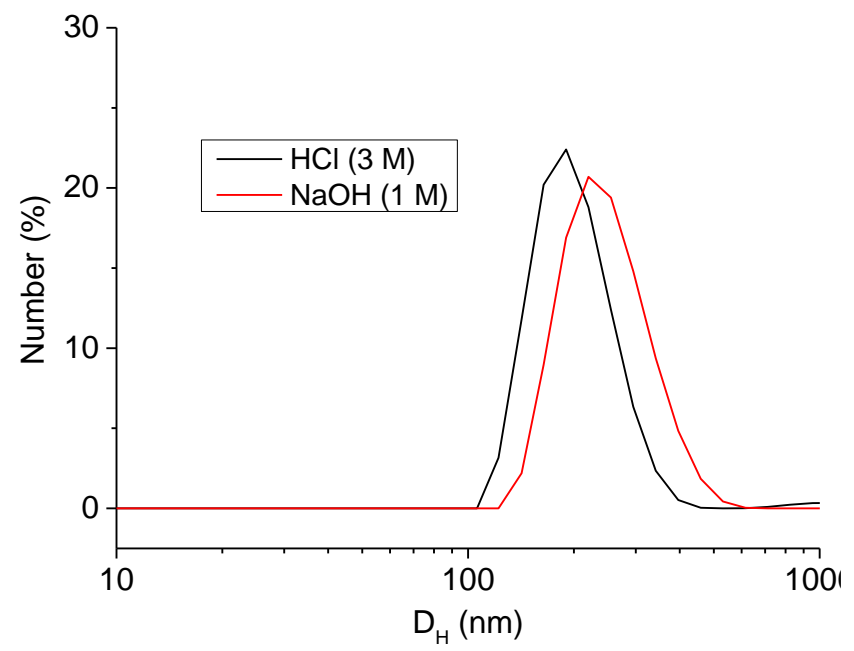

Figure S20. DLS of sCOF-101 $([\mathbf{T 1}]=4 \mathrm{mM})$ in water at $25^{\circ} \mathrm{C}$. To prepare the solution, the $\mathrm{HCl}(3 \mathrm{M})$ or $\mathrm{NaOH}(1 \mathrm{M})$ solution was first prepared and left to stand for 5 hours and then neutralized with $\mathrm{NaOH}$ or $\mathrm{HCl}$ to $\mathrm{pH}=7$.
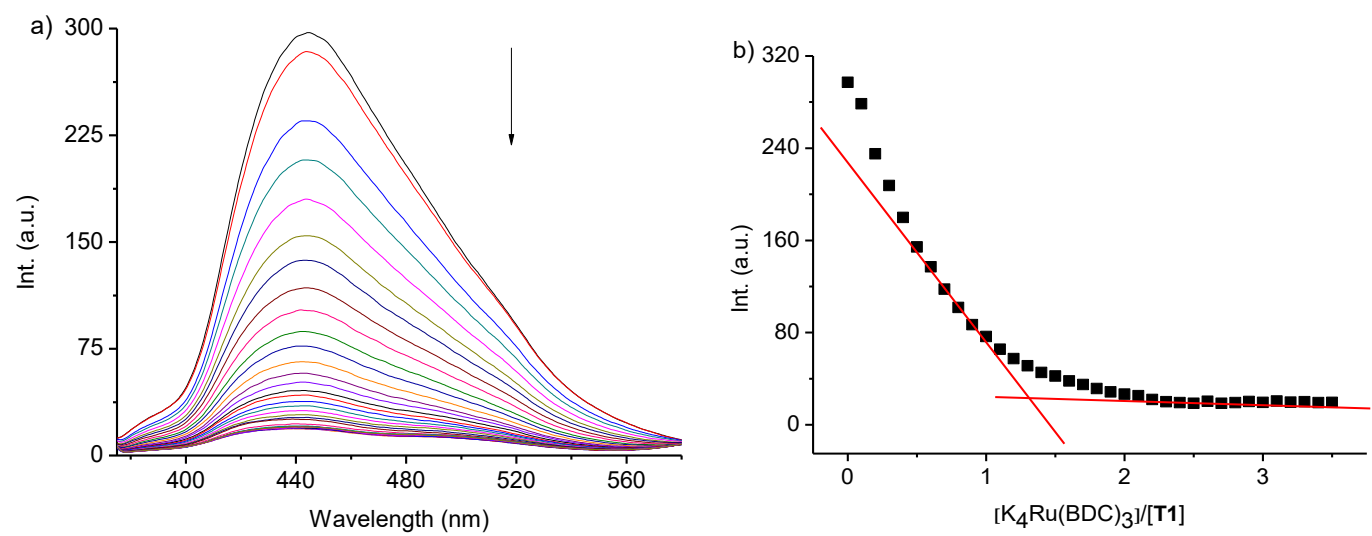

Figure S21. a) The fluorescence spectra of sCOF-101 ([T1 $\left.]=10 \mu \mathrm{M}, \lambda_{\mathrm{ex}}=360 \mathrm{~nm}\right)$ in water in the presence of incremental amount of $\mathrm{K}_{4} \mathrm{Ru}(\mathrm{BDC})_{3}$, and b) plot of the emission at $445 \mathrm{~nm}$ versus $\left[\mathrm{K}_{4} \mathrm{Ru}(\mathrm{BDC})_{3}\right] /[\mathrm{T} 1]$.
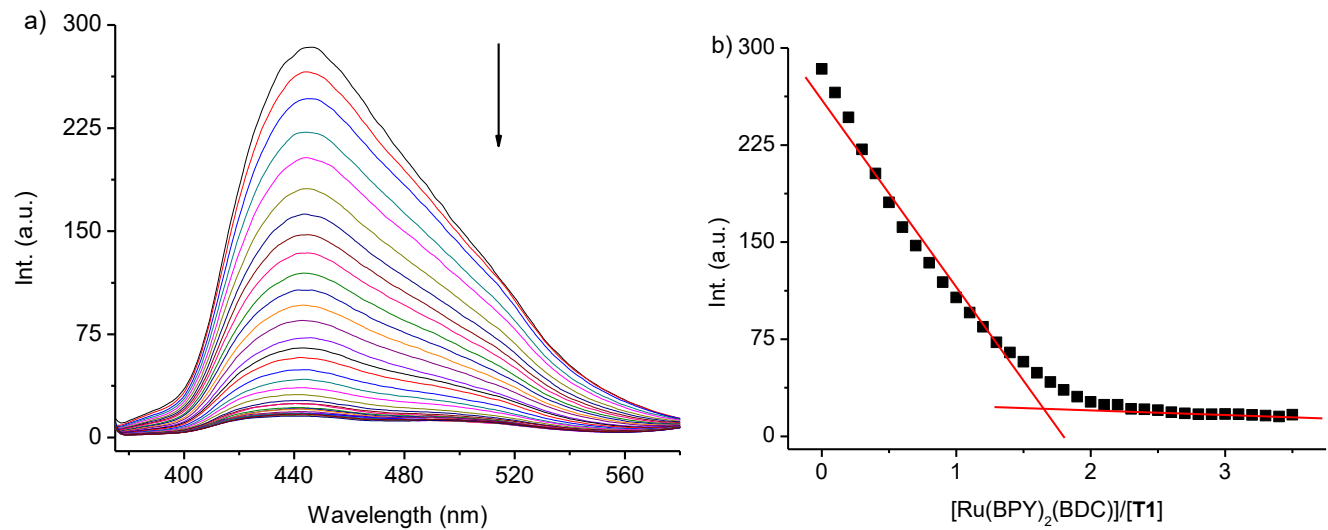

Figure S22. a) The fluorescence spectra of sCOF-101 ([T1 $\left.]=10 \mu \mathrm{M}, \lambda_{\mathrm{ex}}=360 \mathrm{~nm}\right)$ in water in the presence of incremental amount of $\mathrm{Ru}(\mathrm{BPY})_{2}(\mathrm{BDC})$, and $\left.\mathrm{b}\right)$ plot of the emission at 445 $\mathrm{nm}$ versus $\left[\mathrm{Ru}(\mathrm{BPY})_{2}(\mathrm{BDC})\right] /[\mathbf{T} 1]$. 

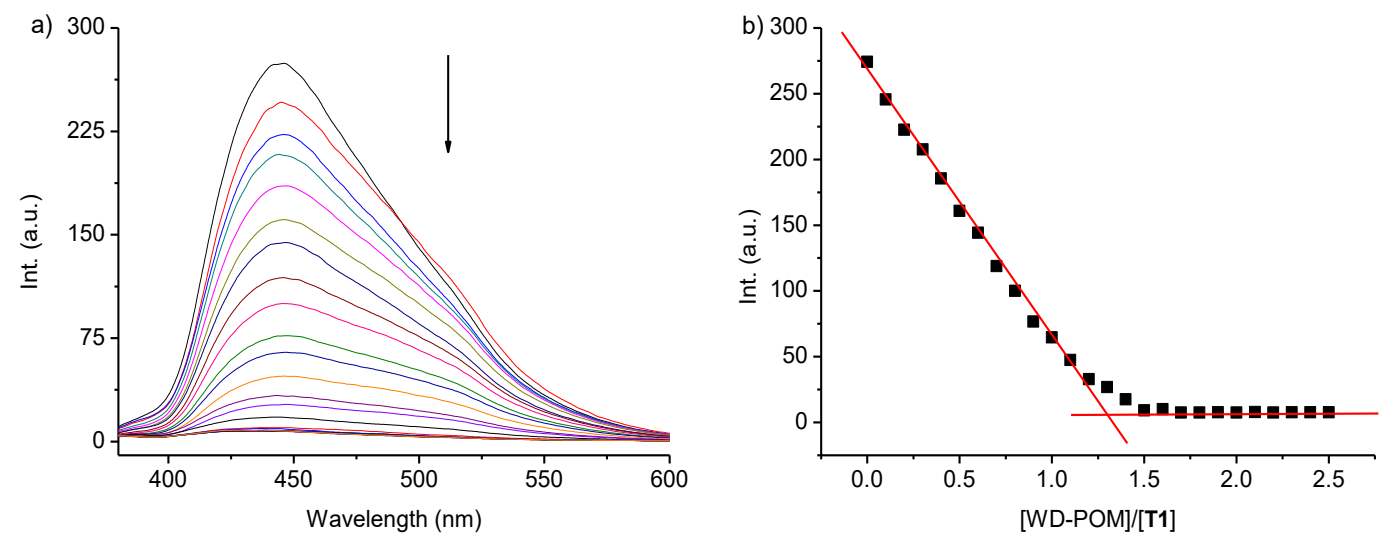

Figure S23. a) The fluorescence spectra of sCOF-101 ([T1 $\left.]=10 \mu \mathrm{M}, \lambda_{\mathrm{ex}}=360 \mathrm{~nm}\right)$ in water in the presence of incremental amount of WD-POM, and b) plot of the emission at $445 \mathrm{~nm}$ versus $[\mathrm{WD}-\mathrm{POM}] /[\mathrm{T} 1]$.
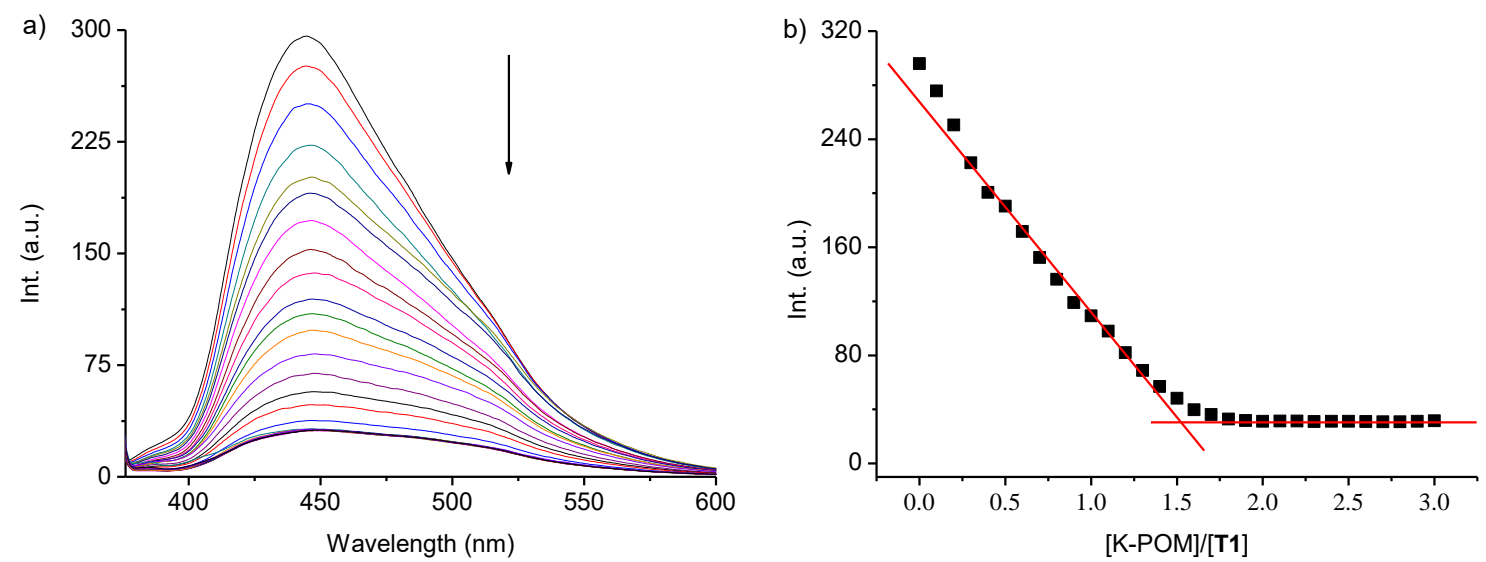

Figure S24. a) The fluorescence spectra of sCOF-101 ([T1 $\left.]=10 \mu \mathrm{M}, \lambda_{\mathrm{ex}}=360 \mathrm{~nm}\right)$ in water in the presence of incremental amount of K1-POM, and b) plot of the emission at $445 \mathrm{~nm}$ versus $[\mathrm{K} 1-\mathrm{POM}] /[\mathbf{T} 1]$.
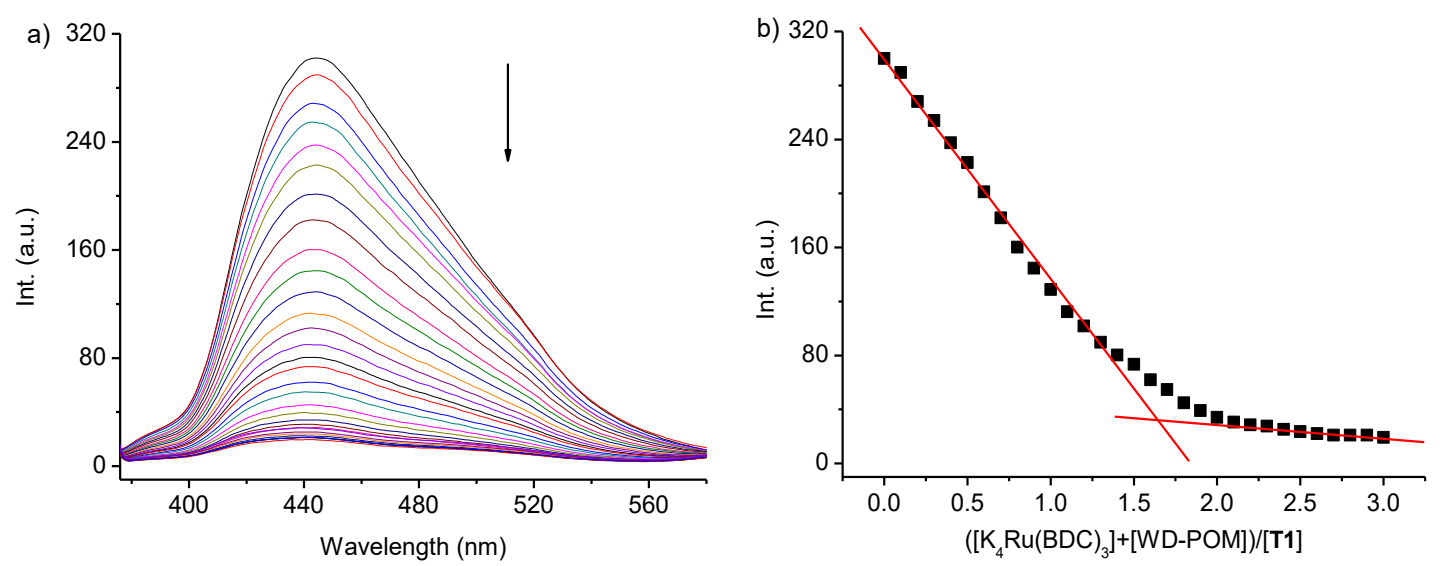

Figure S25. a) The fluorescence spectra of sCOF-101 ([T1 $\left.]=10 \mu \mathrm{M}, \lambda_{\mathrm{ex}}=360 \mathrm{~nm}\right)$ in water in the presence of incremental amount of $\mathrm{K}_{4} \mathrm{Ru}(\mathrm{BDC})_{3}$ and WD-POM (molar ratio $=10: 1$ ), and b) plot of the emission at $445 \mathrm{~nm}$ versus $\left(\left[\mathrm{K}_{4} \mathrm{Ru}(\mathrm{BDC})_{3}\right]+[\mathrm{WD}-\mathrm{POM}]\right) /[\mathrm{T1}]$. 

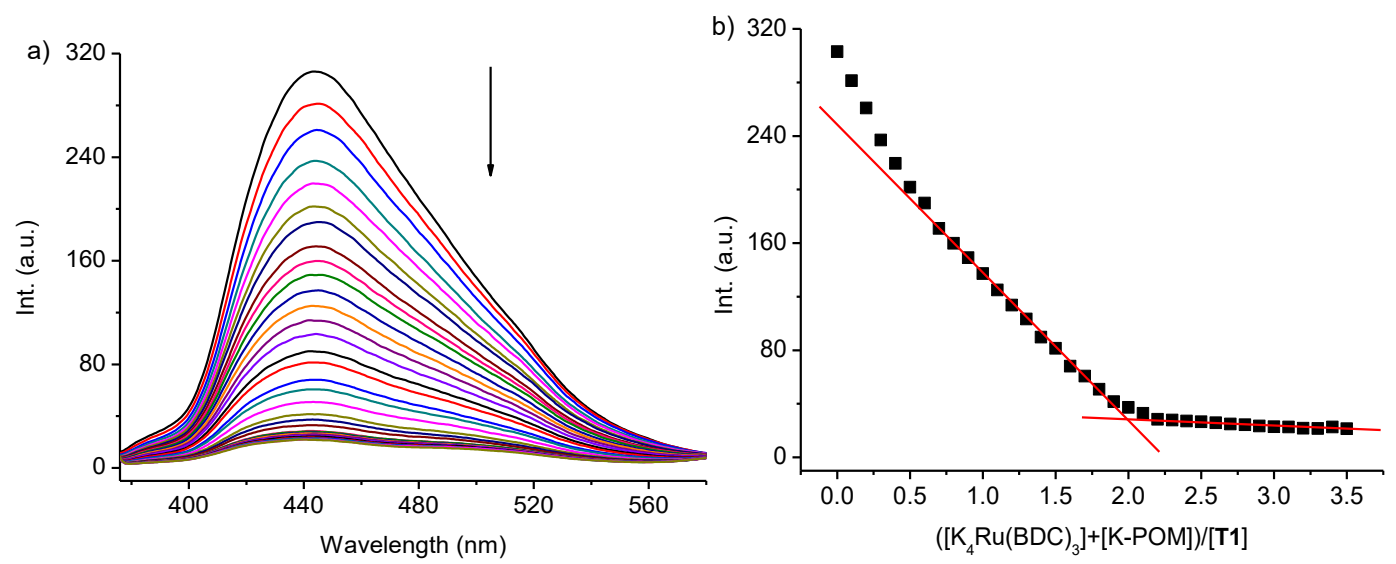

Figure S26. a) The fluorescence spectra of sCOF-101 $\left([\mathrm{T1}]=10 \mu \mathrm{M}, \lambda_{\mathrm{ex}}=360 \mathrm{~nm}\right)$ in water in the presence of incremental amount of $\mathrm{K}_{4} \mathrm{Ru}(\mathrm{BDC})_{3}$ and $\mathrm{K} 1-\mathrm{POM}$ (molar ratio $=10: 1$ ), and b) plot of the emission at $445 \mathrm{~nm}$ versus $\left(\left[\mathrm{K}_{4} \mathrm{Ru}(\mathrm{BDC})_{3}\right]+[\mathrm{K} 1-\mathrm{POM}]\right) /[\mathrm{T} 1]$.

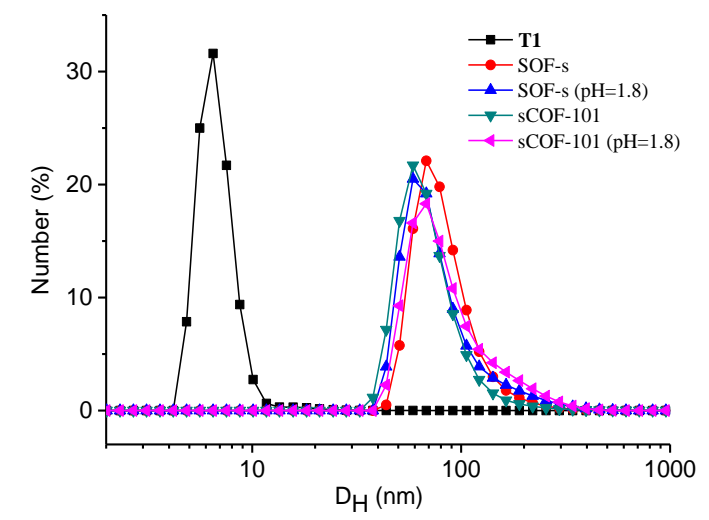

Figure S27. DLS profiles of T1, SOF-s and SCOF-101 in water or dilute hydrochloric acid (pH $=1.8)$ at $25{ }^{\circ} \mathrm{C}$. For all the solutions, $[\mathrm{T1}]=0.1 \mathrm{mM}$.

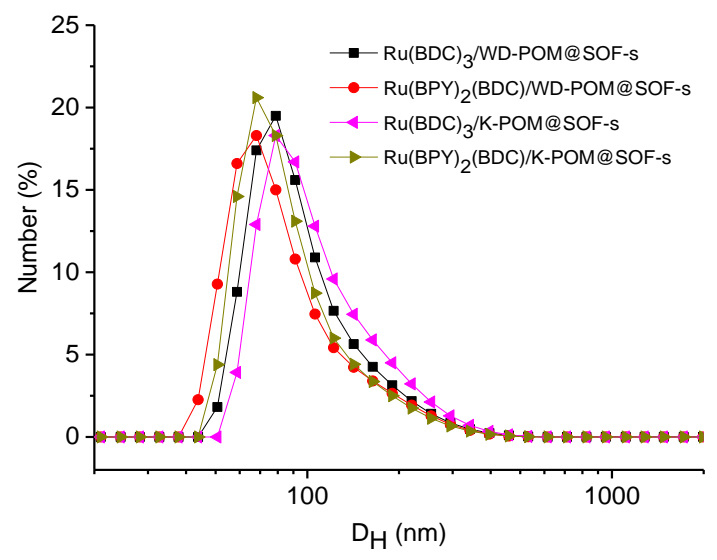

Figure S28. DLS profiles of SOF-s $([\mathbf{T 1}]=0.1 \mathrm{mM})$ in acid aqueous solution $(\mathrm{pH}=1.8$, with $\mathrm{HCl})$ at $25^{\circ} \mathrm{C}$ in the presence of the photosensitizer $(20.0 \mu \mathrm{M})$ and POM catalyst $(2.0 \mu \mathrm{M})$. 


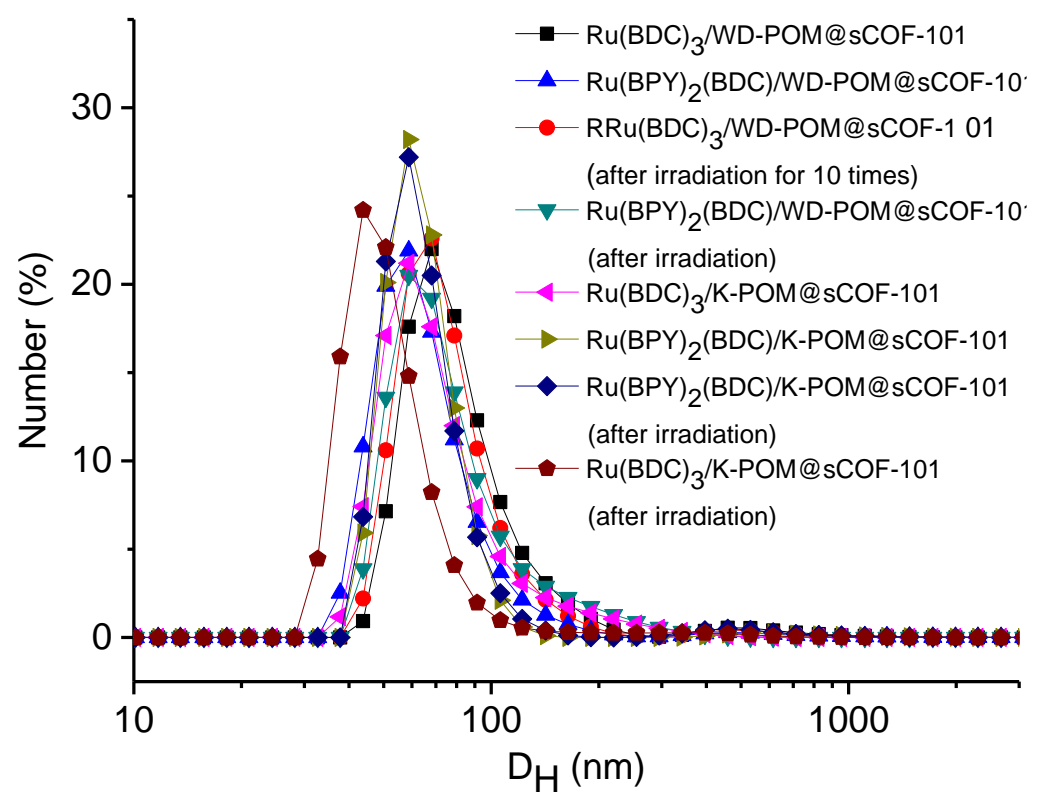

Figure S29. DLS profiles of sCOF-1 $([\mathrm{T} 1]=0.1 \mathrm{mM})$ in acid aqueous solution $(\mathrm{pH}=1.8$, with $\mathrm{HCl})$ at $25{ }^{\circ} \mathrm{C}$ in the presence of the photosensitizer $(20.0 \mu \mathrm{M})$ and POM catalyst $(2.0 \mu \mathrm{M})$ before and after irradiation for 22 hours.
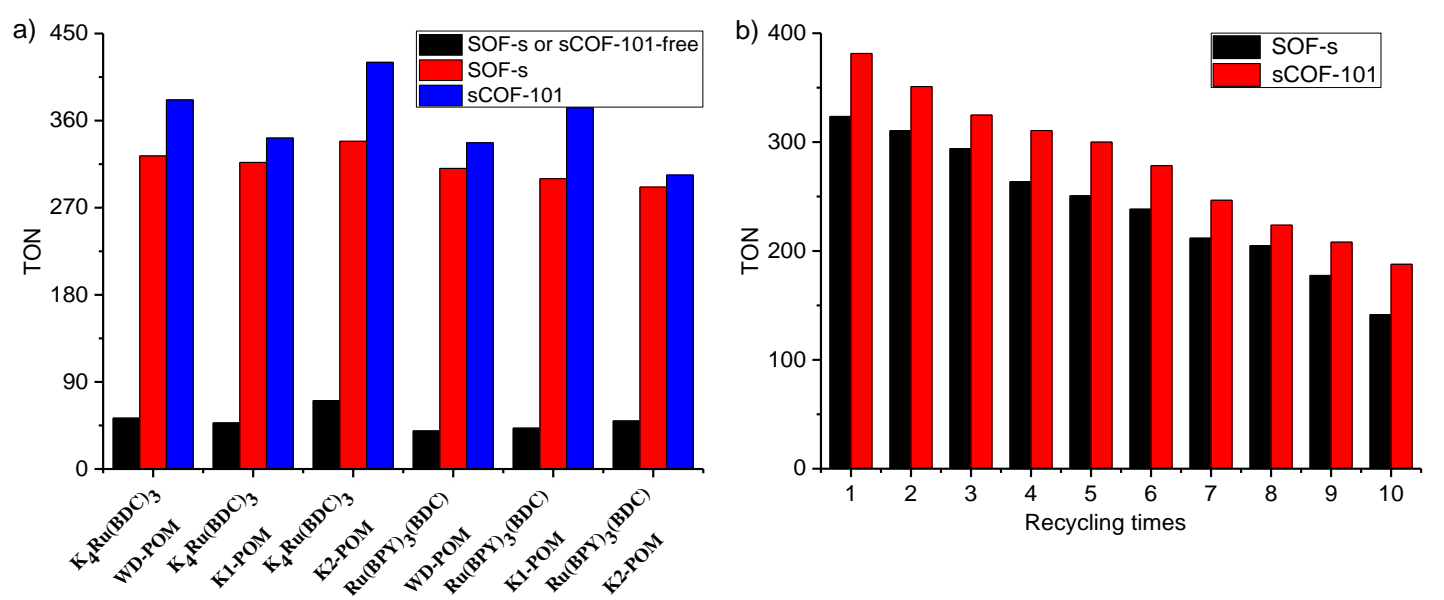

Figure S30. a) TON values at different combinations of the sensitizers and catalysts. b) TON values in the presence of SOF-s and sCOF-101 $([\mathbf{T}]=0.10 \mathrm{mM})$ versus the recycling times. The hydrogen evolution reaction was conducted under irradiation for $22 \mathrm{~h}$ in the acid solution $(\mathrm{pH}=1.8,2.0 \mathrm{~mL})$ containing methanol $(20 \%, \mathrm{v} / \mathrm{v})$, [photosensitizer] $/[$ catalyst $]=10: 1$. 


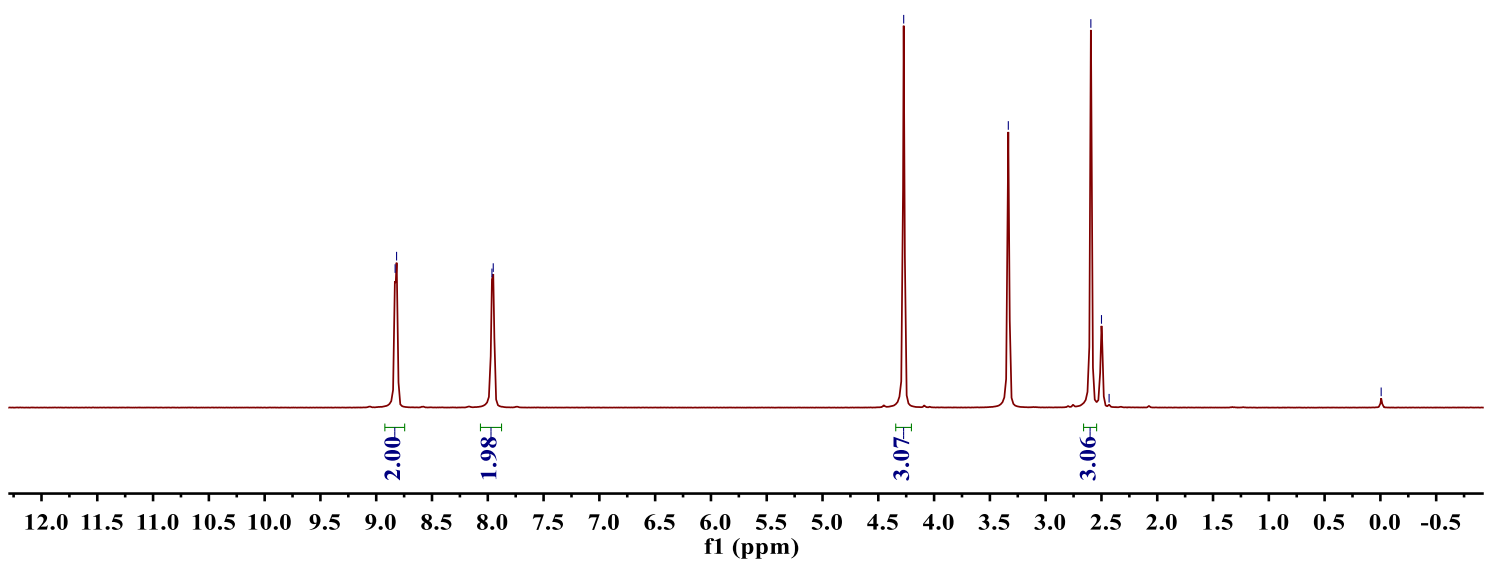

Figure S31. ${ }^{1} \mathrm{H}$ NMR spectrum $(400 \mathrm{MHz})$ of 2 in DMSO- $d_{6}$ at $25{ }^{\circ} \mathrm{C}$.

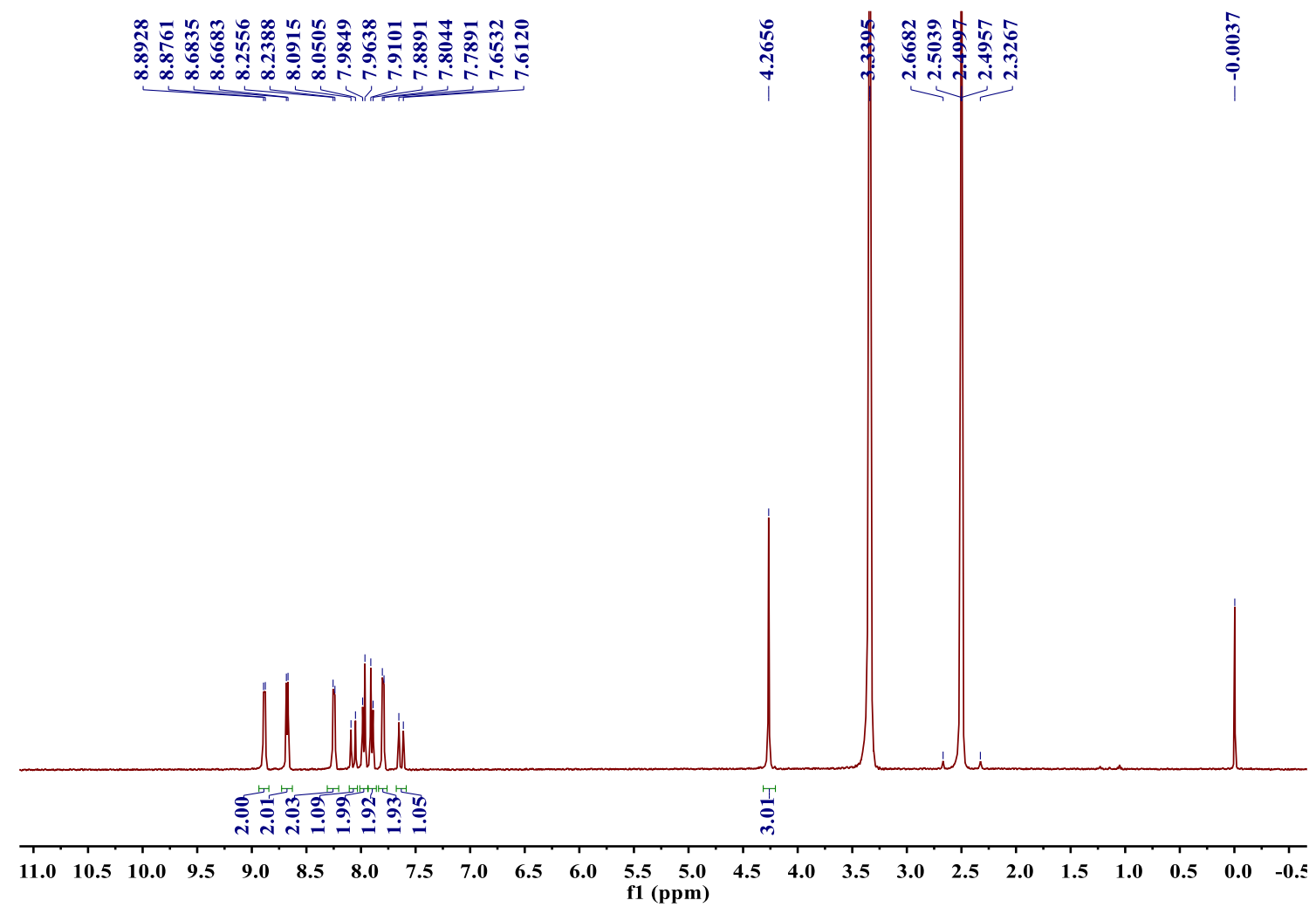

Figure S32. ${ }^{1} \mathrm{H}$ NMR spectrum $(400 \mathrm{MHz})$ of 5 in DMSO- $d_{6}$ at $25{ }^{\circ} \mathrm{C}$. 


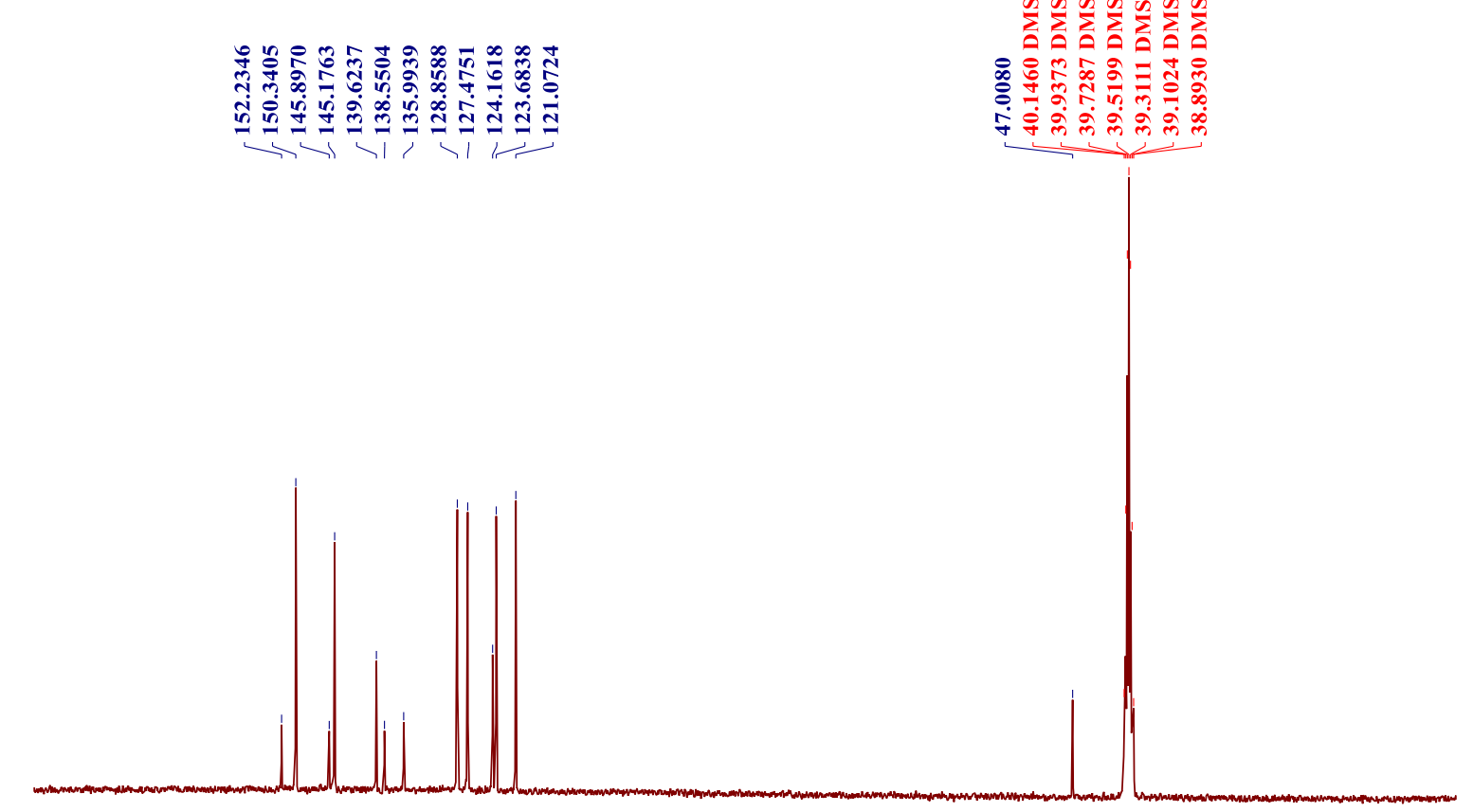

\begin{tabular}{lllllllllllllllllllll}
\hline 180 & 170 & 160 & 150 & 140 & 130 & 120 & 110 & 100 & $\begin{array}{c}90 \\
\text { f1 }\end{array}$ & 80 & 70 & 60 & 50 & 40 & 30 & 20 & 10 & 0
\end{tabular}

Figure S33. ${ }^{13} \mathrm{C}$ NMR spectrum $(400 \mathrm{MHz})$ of 5 in DMSO- $d_{6}$ at $25{ }^{\circ} \mathrm{C}$.

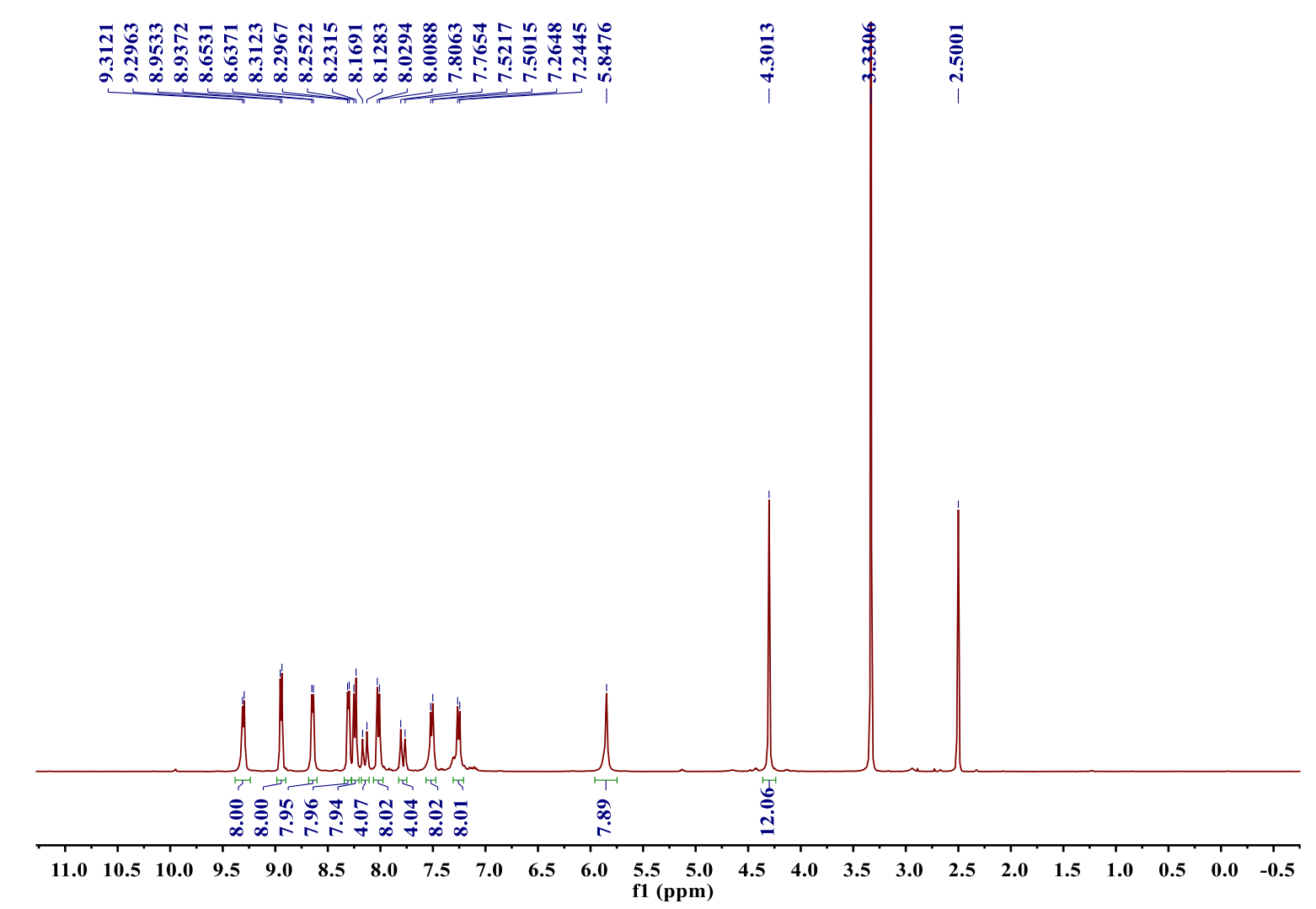

Figure S34. ${ }^{1} \mathrm{H}$ NMR spectrum $(400 \mathrm{MHz})$ of T1 in DMSO- $d_{6}$ at $25{ }^{\circ} \mathrm{C}$. 

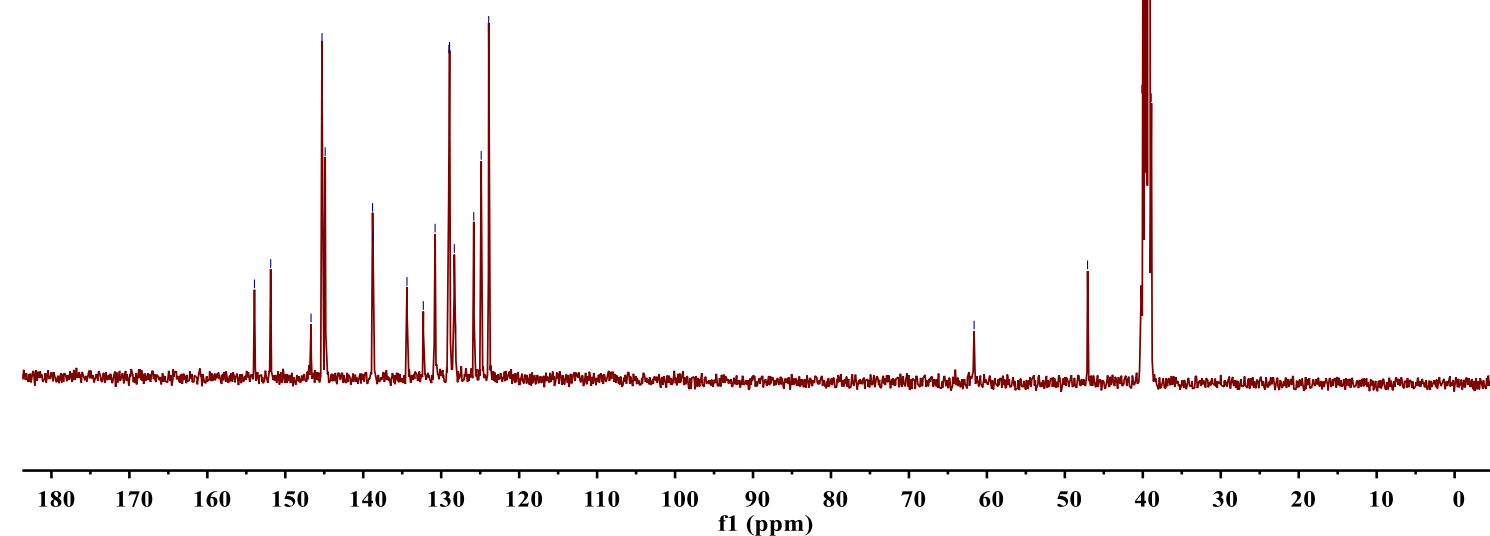

Figure S35. ${ }^{13} \mathrm{C}$ NMR spectrum $(400 \mathrm{MHz})$ of $\mathbf{T 1}$ in DMSO- $d_{6}$ at $25{ }^{\circ} \mathrm{C}$.

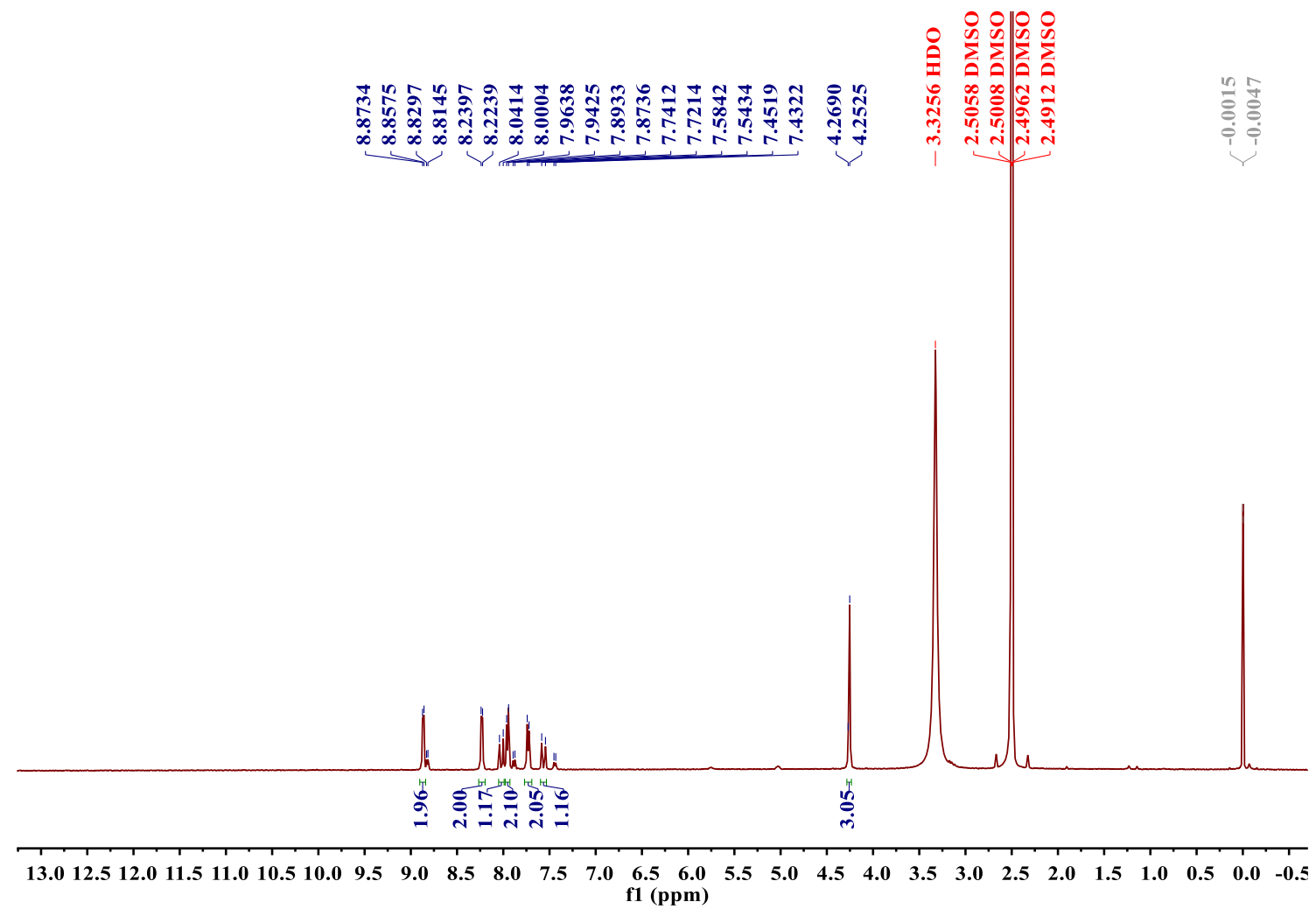

Figure S36. ${ }^{1} \mathrm{H}$ NMR spectrum $(400 \mathrm{MHz})$ of $\mathbf{M 1}$ in DMSO- $d_{6}$ at $25{ }^{\circ} \mathrm{C}$. 


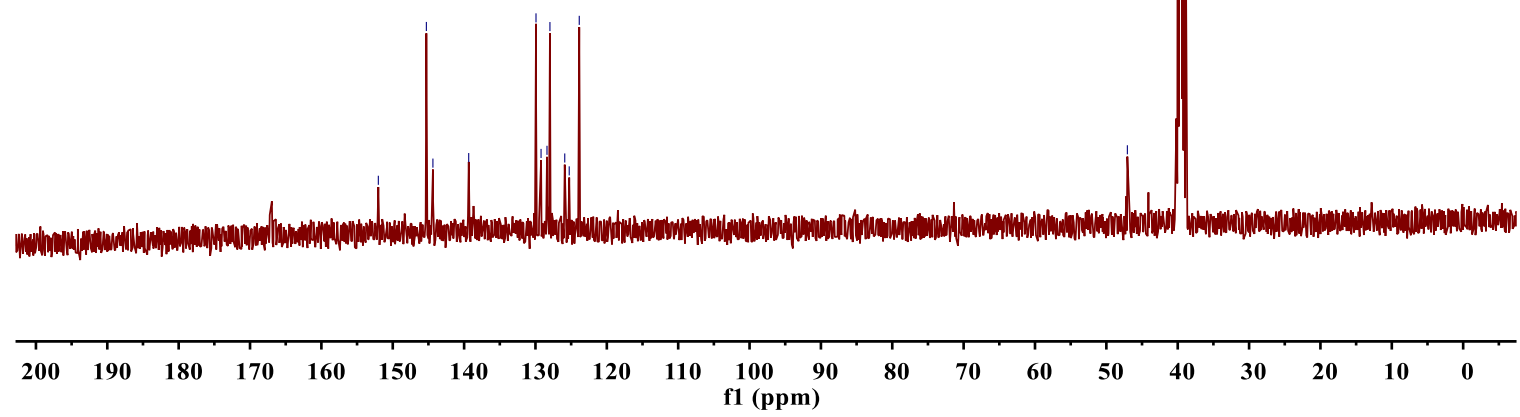

Figure S37. ${ }^{13} \mathrm{C}$ NMR spectrum $(400 \mathrm{MHz})$ of $\mathbf{M 1}$ in DMSO- $d_{6}$ at $25{ }^{\circ} \mathrm{C}$.

\section{Reference:}

(1) Pace, A.; Pierro, P.; Buscemi, S.; Vivona, N.; Clennan, E. L. J. Org. Chem. 2007, 72, 26442646. 